\title{
Cranial morphology of Sinovenator changii (Theropoda: Troodontidae) on the new material from the Yixian Formation of western Liaoning, China
}

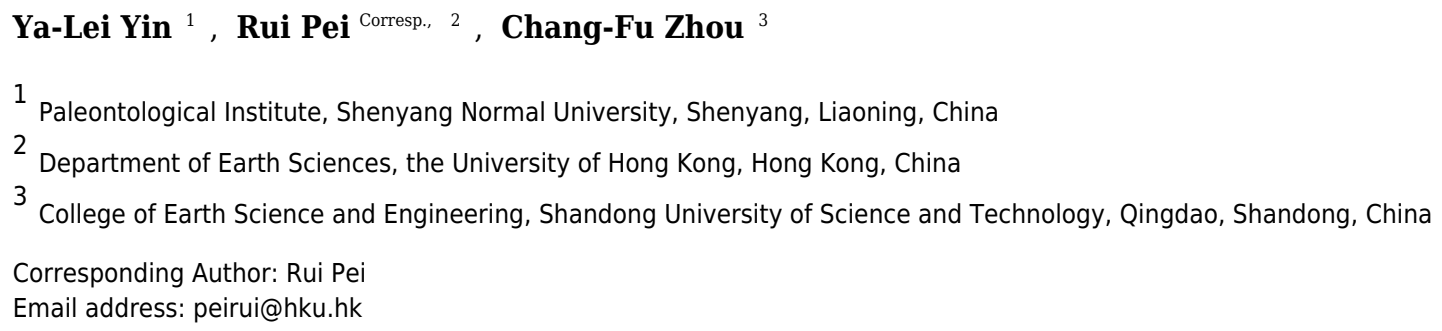

A new three-dimensionally preserved troodontid specimen consisting of most of the skull, partial mandibles and six articulated cervical vertebrae (PMOL-AD00102) from the Early Cretaceous Yixian Formation of Beipiao, western Liaoning, China is identified as Sinovenator changii on the basis of a surangular with a "T"-shaped cross-section. Highresolution computed tomographic data for the skull of this new specimen facilitated a detailed description of the cranial anatomy of Sinovenator changii. New diagnostic features of Sinovenator changii include a well-developed medial shelf on the jugal, a slender bar in the parasphenoid recess, a lateral groove on the pterygoid flange of the ectopterygoid, and the lateral surface of the anterior cervical vertebrae bearing two pneumatic foramina. Our new observation confirms that the braincase of Sinovenator is not as primitive as previously suggested, although it still shows an intermediate state between derived troodontids and non-troodontid paravians in having an initial stage of the subotic recess and the otosphenoidal crest. Additionally, this new specimen reveals some novel and valuable anatomical information of troodontids regarding the quadrate-quadratojugal articulation, the stapes, the epipterygoid and the atlantal ribs. 
1 Cranial morphology of Sinovenator changii (Theropoda: Troodontidae) on the new material

2 from the Yixian Formation of western Liaoning, China

3

\section{Ya-Lei Yin ${ }^{1}$, Rui Pei ${ }^{2}$ and Chang-Fu Zhou ${ }^{3}$}

$4 \quad{ }^{1}$ Paleontological Institute, Shenyang Normal University, Shenyang, Liaoning, China

$5 \quad 2$ Department of Earth Sciences, the University of Hong Kong, Hong Kong, China

$6{ }^{3}$ College of Earth Science and Engineering, Shandong University of Science and Technology,

7 Qingdao, Shandong, China

8

9 Corresponding author: Rui Pei, peirui@hku.hk 


\section{ABSTRACT}

A new three-dimensionally preserved troodontid specimen consisting of most of the skull,

14 partial mandibles and six articulated cervical vertebrae (PMOL-AD00102) from the Early

Cretaceous Yixian Formation of Beipiao, western Liaoning, China is identified as Sinovenator

changii on the basis of a surangular with a "T"-shaped cross-section. High-resolution computed

tomographic data for the skull of this new specimen facilitated a detailed description of the

cranial anatomy of Sinovenator changii. New diagnostic features of Sinovenator changii include

a well-developed medial shelf on the jugal, a slender bar in the parasphenoid recess, a lateral

groove on the pterygoid flange of the ectopterygoid, and the lateral surface of the anterior

cervical vertebrae bearing two pneumatic foramina. Our new observation confirms that the

braincase of Sinovenator is not as primitive as previously suggested, although it still shows an

intermediate state between derived troodontids and non-troodontid paravians in having an initial

stage of the subotic recess and the otosphenoidal crest. Additionally, this new specimen reveals quadratojugal articulation, the stapes, the epipterygoid and the atlantal ribs. 


\section{INTRODUCTION}

32 Troodontidae is a group of small to middle-bodied theropod dinosaurs, and is well known from the Cretaceous rocks of Asia and North America (Makovicky \& Norell, 2004). It has a high morphological relevance in understanding the avian origin (e.g., Xu et al., 2002). Many exquisitely preserved troodontid fossils have been reported from the Early Cretaceous Jehol Biota in western Liaoning and adjacent areas in the last two decades, such as Sinovenator, Mei, Sinusonasus, Jinfengopteryx, Daliansaurus, Liaoningvenator and Jianianhualong (e.g., Xu et al., 2002; Xu \& Norell, 2004; Xu \&Wang, 2004; Ji et al., 2005; Shen et al., 2017a; Shen et al., 2017b;

$X u$ et al., 2017). These discoveries shed new lights on the evolution of troodontids and the origin of birds (Xu et al., 2002; Xu \& Norell, 2004; Xu et al., 2017). Among these recently reported troodontids, Sinovenator, with similarities to both troodontids and dromaeosaurids, has been believed to be one of the most basal members of Troodontidae, and plays a key role in understanding the origin and the early evolution of this family (Xu et al., 2002). However, only a 
52 specimen is referred to Sinovenator changii based on proposed diagnostic characters of this

53 species, such as a "T"-shaped cross-section of the surangular. In this study, we also employed

54 high-resolution computed tomographic (CT) technology to reveal the cranial anatomy of PMOL-

55 AD00102 that is still concealed in the matrix. The new anatomical information not only enriches

56 our knowledge of the osteology of Sinovenator, but also provides an opportunity to investigate

57 the evolutionary trends in the palate and cranium of troodontids.

\section{MATERIALS \& METHODS}

PMOL-AD00102 is preserved in three dimensions with a nearly complete skull, partial mandibles and six articulated cervical vertebrae (Figs. 2-15). The skull lacks the rostral portion anterior to the antorbital fenestra and is slightly anterolaterally compressed. The mandibles lack the rostral portions anterior to the last fourth dentary tooth. The specimen represents an adult individual as the neural arch and centrum of each cervical vertebra are fused. were scanned by High-resolution X-ray CT scanner (Nikon XT H 320 LC) at China University were done using VG Studio Max 2.2 (Volume Graphics, Heidelberg, Germany).

SYSTEMATIC PALEONTOLOGY

Theropoda Marsh, 1881

Maniraptora Gauthier, 1986 
73 Troodontidae Gilmore, 1924

74 Sinovenator changii Xu et al., 2002

75 Holotype

76 IVPP V12615 (Institute of Vertebrate Paleontology and Paleoanthropology), a partial skull and

77 skeleton.

78

\section{Paratype}

IVPP V12583, an articulated partial postcranial skeleton.

\section{Referred Specimen}

PMOL-AD00102 (Paleontological Museum of Liaoning), a partial skull and mandibles missing only the rostral portions, and six articulated cervical vertebrae (Figs. 2-15).

\section{Locality, Horizon and Age}

Lujiatun, Shangyuan, Beipiao City, western Liaoning, China (Fig. 1); the lowest part of the Yixian Formation, ca. $126 \mathrm{Ma}$ (Chang et al., 2017). This specimen was collected from villagers at Lujiatun. The exact location where this specimen was discovered is unknown, but the greyish tuffaceous matrix and the three-dimensionally preserved skeleton strongly indicate that PMOLAD00102 was from the tuffaceous fossil bed at the lowest part of the Yixian Formation, the major outcrop of which is located at Lujiatun.

\section{Revised Diagnosis}

Sinovenator is distinguished from other troodontids in having the following autapomorphies (newly added diagnostic features marked by*): well-developed medial shelf on the jugal*; slender bar in the parasphenoid recess*; lateral groove on the pterygoid flange of the 
94 ectopterygoid*; surangular "T"-shaped in cross-section; lateral surface of the anterior cervical

95 vertebrae bearing two pneumatic foramina*; and prominent lateral cnemial crest continuous with

96 the fibular crest.

\section{DESCRIPTION}

\section{SKULL}

The skull preserves partial antorbital fenestrae, large orbits and temporal fenestrae (Figs. 2-4).

The preserved portion of the skull is about $78 \mathrm{~mm}$ long along the buccal margin from the anteroventral corner of the antorbital fenestra to the distal end of the articular joint. The antorbital fenestra is probably sub-rectangular as in Sinusonasus (see figs. 1 and 2 in $X u \& W a n g$, 2004), and the anterior margin of the antorbital fenestra is not complete. The anteroposterior length of the ventral margin of the antorbital fenestra is about $25 \mathrm{~mm}$, larger than that of the holotype (IVPP V12615, $14 \mathrm{~mm} ; X u, 2002)$. The orbit is circular with a maximum diameter of about $40 \mathrm{~mm}$.

\section{Maxilla}

Both maxillae are partially preserved (Figs. 2-4). A fragmentary ascending process of the maxilla is preserved on the right side of the skull. Laterally, it has a tapering tip and contacts the anterior process of the lacrimal, both forming the dorsal margin of the antorbital fenestra (Figs. 3 and 4B). Only the ventral portion of the interfenestral bar is preserved on the right side of the

114 skull, and the interfenestral bar appears to be vertical, as in the holotype (Xu et al., 2002) and 
115 Sinusonasus ( $X u \&$ Wang, 2004), forming the anterior margin of the antorbital fenestra. The

116 ventral ramus (jugal process) of the maxilla is slender, as typical of troodontids, forming the

117 ventral margin of the antorbital fenestra. The maxillary ventral ramus lacks its ventral portion,

118 and is shattered with only its posterior portion preserved as two shelves (Fig. 4B). The two

119 shelves seemingly form a groove to receive the anterior end of the suborbital process of the jugal,

120 as reported in Liaoningvenator (Shen et al., 2017b). Medially, the palatal shelf is well developed

121 with a vaulted medial margin (Fig. 4B), and possibly contacts the maxillary process of the

122 palatine. A foramen pierces through the middle portion of the palatal shelf of the maxilla (Fig.

123 4B).

125 Nasal

126 Only the posterior portions of the nasals are preserved (Fig. 4A). The maximum transverse width

127 of the nasals is $7.9 \mathrm{~mm}$. The dorsal surface of the nasal is smooth. As in Almas (Pei et al., 2017a),

Byronosaurus (Makovicky et al., 2003) and Saurornithoides (Norell et al., 2009), a row of

foramina develops on the anterior part of the dorsal surface of the nasal (Fig. 4A), and opens into

the nasal cavity. As in the holotype (Xu et al., 2002) and Sinusonasus (Xu \& Wang, 2004), the

anterolateral edge of the nasal expands laterally above the antorbital fenestra, forming a small

lateral shelf that overlaps the maxilla and the lacrimal (Fig. 3). The nasal is slightly vaulted

medial to the lateral shelf. A ridge participates to the lateral wall of the lacrimal duct ventral to

the nasal lateral shelf. Posterior to the shelf, the nasal articulates with the lacrimal along a 
136 level of the preorbital bar. As in Zanabazar (Norell et al., 2009) and Liaoningvenator (Shen et al.,

$1372017 b$ ), the posterior parts of the nasals seemingly form a V-shaped notch in dorsal view (Fig.

138 4A), overlapping the frontals.

\section{Lacrimal}

141 The lacrimal is well preserved on the right side (Figs. 3 and 5). As in other deinonychosaurians,

142 this bone is "T"-shaped with an anterior process, a posterior process and a preorbital bar (ventral

143 process). The anterior and posterior processes are dorsally positioned along the skull roof.

144 Medially, a large fossa is present at the junction of the anterior process, the posterior process and 145 the preorbital bar (Fig. 5B).

146 As in other troodontids (Turner, Makovicky \& Norell, 2012), the anterior process is longer

147 than the posterior process (Fig. 5), though the exposed portion of the anterior process is almost as

148 long as the posterior process because the anterior tip of the anterior process is obscured by the 149 nasal anterolateral shelf in dorsal and lateral views (Figs. 3 and 4A). As in Jianianhualong (Xu et 150 al., 2017), Sinusonasus (Xu\& Wang, 2004) and Almas (Pei et al., 2017a), the anterior process is 151 similar in length to the preorbital bar (Fig. 5). The anterior process points anteroventrally and 152 makes an acute angle with the preorbital bar in lateral view. The anterior process has a limited contact with the maxilla rostrally, and forms most of the dorsal margin of the antorbital fenestra,

154 as in Xixiasaurus (Lü et al., 2010) and Byronosaurus (Makovicky et al., 2003). The lacrimal duct 155 is developed along the anterior process lateroventrally, and the duct opens laterally on the 156 junction between the anterior process and the preorbital bar (Fig. 5B), as in Mei (Gao et al., 
157 2012), Byronosaurus (Makovicky et al., 2003), Troodon (Currie, 1985), and Sinornithoides

158 (Currie \& Dong, 2001), but in contrast to dromaeosaurids and other non-avian theropods in

159 which the lacrimal duct penetrates the preorbital bar (Currie \& Dong, 2001; Pei et al., 2014).

160 Dorsal to the lacrimal foramen, the anterior process has a lateral extension (Fig. 5A), as in $M e i$

161 (Gao et al., 2012). Ventral to the lacrimal foramen, a small shallow depression is present (Fig.

$1625 \mathrm{~A})$.

The posterior process is mediolaterally broad, forming the anterodorsal border of the orbit.

164

The posterior process projects posterodorsally, making an obtuse angle with the preorbital bar. It bears a laterally expanded supraorbital crest anterodorsal to the orbit (Figs. 3, 4A and 5A), as in most troodontids (Pei et al., 2017a). The dorsal surface of the posterior process is smooth, in contrast to the rugose condition in Dromaeosaurus (Currie, 1995). The posterior process is bifurcated with a longer dorsal ramus in lateral view (Figs. 3 and 5A) as in Jianianhualong (Xu et al., 2017). The medial surface of the posterior process bears a shallow and sub-triangular groove that widens posteriorly between the dorsal and ventral rami (Fig. 5B).

The preorbital bar forms the posterior margin of the antorbital fenestra, and slightly curves anteroventrally at its ventral portion (Fig. 2). As in dromaeosaurids, the preorbital bar does not contact the maxilla ventrally (Currie, 1995). The preorbital bar is everted, and the lateral surface of its upper portion becomes the posterior surface at the lower portion. The lower portion of the preorbital bar becomes anteroposteriorly compressed. A distinct groove extends ventrally along the posterolateral surface of the preorbital bar. Anterior to the groove, a lateral flange is present along the anterolateral surface of the preorbital bar (Figs. 2, 3 and 5A), as in other troodontids 
178 (Xu et al., 2017). The ventral end of the preorbital bar locates in a long and shallow groove on 179 the jugal, which makes the preorbital bar seemingly able to slide along this groove. The preorbital bar makes a right angle with the suborbital process of the jugal (Fig. 2).

\section{Postorbital}

The left postorbital is incompletely preserved and its posterior process is missing (Fig. 2). The anterior process of the postorbital is fragmentary, and probably upturns and contacts the postorbital process of the frontal, based on the upturned articular surface of the postorbital process of the frontal. Laterally, the main body of the postorbital is depressed. The anterior edge of the postorbital curves and forms the posterodorsal margin of the orbit. The distal part of the ventral process is missing but possibly articulates with the postorbital process of the jugal.

\section{Squamosal}

The left squamosal is well preserved, only missing its rostral process, and the right squamosal is represented by a medial process (Figs. 2 and 3). The main body of the squamosal wraps the quadrate head with an articular cotylus, and bears a distinct lateral recess as in derived troodontids such as Almas (Pei et al., 2017a) and Linhevenator (Xu et al., 2011). The quadratojugal process of the squamosal tapers ventrally in lateral view. The anterior edge of the quadratojugal process is mediolaterally thinner than its posterior edge as in Troodon (Currie, 1985). Distally, this process is isolated from the quadrate shaft, likely due to taphonomic distortion. However, it possibly would have contacted the upper portion of the quadrate shaft in 
199

200

201

202

203

204

205

206

207

208

209

210

211

212

213

214

215

216

217

218

219

life. The preserved posterior process of the squamosal is downturned and wedged between the quadrate anteriorly and the paroccipital process posteriorly. The medial process of the squamosal articulates with the anterior surface of the nuchal crest formed by the parietal.

\section{Jugal}

The left jugal is well preserved (Figs. 2, 6A and 6B). The jugal of the new specimen is triradiate, with a suborbital process, a postorbital process and a quadratojugal process as in other deinonychosaurians, e.g., Gobivenator (Tsuihiji et al., 2014), Almas (Pei et al., 2017a), Microraptor (Pei et al., 2014) and Velociraptor (Barsbold \& Osmólska, 1999). The anteroposterior length of the left jugal is $56.8 \mathrm{~mm}$.

The anterior tip of the suborbital process inserts into the ventral ramus of the maxilla (Fig. 2). In lateral view, the suborbital process tapers anteriorly, and contributes to the posteroventral corner of the antorbital fenestra. In dorsal view, the dorsal margin of the suborbital process is slightly convex laterally (Fig. 6A). The suborbital process is dorsoventrally shallow ventral to the antorbital fenestra and the anterior half of the orbit. It becomes dorsoventrally deep ventral to the posterior half of the orbit, reaching twice the depth of its anterior portion (Fig. 2). Posterior to the antorbital fenestra, the suborbital process bears a longitudinal ridge along its ventral portion of the lateral surface which terminates below the midpoint of the orbit as in Linhevenator (Xu et al., 2011). A longitudinal groove is developed in the lateral surface of the suborbital process dorsal to this ridge as in the holotype (Xu, 2002), Mei (Xu \& Norell, 2004), Linhevenator (Xu et al., 2011), and Zanabazar (Norell et al., 2009). Ventral to this ridge, a shallow and narrow 
220

221

222

223

224

225

226

227

228

229

230

231

232

233

234

235

236

237

238

239

240

groove is developed on the lateroventral surface of the suborbital process (Fig. 4B), and this

groove starts below the preorbital bar and terminates posteriorly below the midpoint of the

suborbital portion of the suborbital process. The suborbital process has a medial shelf (Figs. 4B

and 6) close to the ventral margin extending from the point just anterior to the preorbital bar to

the level anterior to the expanded suborbital portion of the jugal, and this feature is reported in

troodontids for the first time. A shallow groove is developed dorsal to the shelf (Fig. 6A). This

groove articulates with the preorbital bar of the lacrimal. Medially, a deep fossa is present at the

posterior end of the groove and dorsal to a depression (Figs. 6A and 6B). A shallow trough is

developed anteroventral to the depression, separated from the groove by the medial shelf (Figs.

$6 \mathrm{~A}$ and $6 \mathrm{~B})$. Further anteriorly, a rough articular surface for the ectopterygoid is located on the

medial surface of the dorsoventrally thickened portion of the medial shelf (Fig. 6B).

The postorbital process slightly inclines posterodorsally, and the dorsal half of the

postorbital process is fragmentary (Fig. 6B). The postorbital process has a broad and

anterolaterally oblique surface possibly for articulating with the jugal process of the postorbital

(Fig. 6A). In medial view, a low ridge develops on the postorbital process of the jugal as in the

holotype $(X u, 2002)$. This ridge terminates at the base of the postorbital process (Figs. 6A and

$6 B)$.

The quadratojugal process tapers posteriorly and splits into two prongs for the reception of the jugal process of the quadratojugal (Figs. 2 and 6B). The dorsal prong is longer than the ventral prong. The jugal process of the quadratojugal articulates with the lateral surface of the dorsal prong and the medial surface of the ventral prong (Fig. 6B). 


\section{Quadratojugal}

243 The left quadratojugal is preserved, and it is comprised of a jugal process and a squamosal

244 process (Fig. 2). In lateral view, the quadratojugal is reversed L-shaped as in Sinornithoides

245 (Russell \& Dong, 1993), Almas (Pei et al., 2017a), Archaeopteryx (Elzanowski \& Wellnhofer,

246 1996) and Anchiornis (Pei et al., 2017b), different from the inverted "T"-shaped quadratojugal in

247 dromaeosaurids (Currie, 1995). Unlike dromaeosaurids, the quadratojugal does not contact the

248 squamosal (Fig. 2), in agreement with $\mathrm{Mei}$ (Xu \& Norell, 2004), Sinornithoides (Russell \& Dong,

249 1993) and Gobivenator (Tsuihiji et al., 2014). The main body of the quadratojugal covers the

250 ventral portion of the quadrate laterally and bears a socket on its anterodorsal surface. The jugal

251 process of the quadratojugal is damaged, with only the anterior-most portion that inserts into a

252 slot on the quadratojugal process of the jugal preserved. The squamosal process is slender and

253 dorsally projected. As in Sinornithoides (Russell \& Dong, 1993), the squamosal process wraps

254 the quadrate shaft posteriorly.

255

256 Quadrate

257 The left quadrate is slightly fractured and the right quadrate lacks the anterior part of its

258 pterygoid ramus (Figs. 4B and 7). The quadrate has a height of approximately $20 \mathrm{~mm}$.

259 The quadrate head is singular in dorsal view. It is anteromedial-posterolaterally wide, and is

260 wrapped by the squamosal. The quadrate head is exposed extensively in lateral view (Fig. 2).

261 Unlike dromaeosaurids, the quadrate body does not have a triangular lateral process. The anterior 
262 surface of the quadrate body above the mandibular articulation is concave in anterior view. In

263 posterior view, the pneumatic fenestra is located in the middle portion of the quadrate body (Figs.

264 7A and 7C) as in the holotype (Xu et al., 2002) and other troodontids (Makovicky \& Norell,

265 2004). The quadrate shaft bears a strong posterior curvature. In lateral view, the dorsal half of the

266 quadrate shaft is wider than its ventral half and has a smooth lateral surface. The quadrate ridge

267 is developed medially along the quadrate shaft (Fig. 7C).

268 Two asymmetric condyles are present for the mandibular articulation. A shallow diagonal

269 sulcus separates these two condyles (Fig. 4B). The medial condyle is larger than the lateral

condyle, similar to the condition in the unnamed Early Cretaceous troodontid IGM 100/44

271 (Barsbold, Osmólska \& Kurzanov, 1987), Saurornithoides (Norell \& Hwang, 2004),

Dromaeosaurus (Colbert \& Russell, 1969) but unlike the condition in Sinornithosaurus (Xu \&

Wu, 2001) and Velociraptor (Barsbold \& Osmólska, 1999) in which the lateral condyle is larger.

Dorsolateral to the lateral condyle, the quadrate bears a sub-trapezoidal facet that is overlapped

by the quadratojugal.

Laterally, the pterygoid ramus is sheet-like and overlaps the quadrate process of the

pterygoid. The dorsal edge of the pterygoid ramus descends anteriorly and is thickened as in

Sinornithosaurus $(X u, 2002)$. In medial view, the pterygoid ramus bears a concavity that

becomes larger and wider ventrally. Anterior to the concavity, an anteriorly bowed low ridge

defines the posterior boundary of the articular surface with the quadrate process of the pterygoid 
283

284 285

286

287

288

289

290

291

292

293

294

295

296

297

298

299

300

301

302

303

\section{Pterygoid}

The left pterygoid is nearly completely preserved, and the right pterygoid has its main body and the anterior portion of the quadrate ramus missing (Fig. 7). Dorsally, the anterior end of the pterygoid seemingly contacts the other pterygoid, and a long and tear-shaped interpterygoid vacuity is present along the midline of the palate (Fig. 7A). It is unclear whether the two pterygoids contact posteriorly due to the incompleteness of the right pterygoid. However, such a contact is unlikely based on the shape of the left pterygoid. If this morphology is correctly interpreted here, it would resembles the condition in Archaeopteryx (Mayr et al., 2007) and some dromaeosaurids, such as Deinonychus (see fig. 5 in Ostrom, 1969) and Dromaeosaurus (see fig. 1C in Currie, 1995), but unlike the condition in Saurornithoides (Norell et al., 2009) and Gobivenator (see fig. 5 in Tsuihiji et al., 2014), in which the two elements contact and nearly contact with each other, respectively. The anterior (palatine) ramus is vertical and long, forming the medial margin of the pterygopalatine fenestra. The anterior half of the anterior ramus deepens anteriorly, while its posterior half becomes a slender rod (Fig. 7C). In lateral view, the anterior ramus bears a narrow and shallow trough along the posterior half of the ramus. Posterior to the anterior ramus, the main body of the pterygoid expands laterally and becomes a thin sheet (Fig. 4B). The pterygoid flange develops as a distinct lateral process at the posterior end of the main body, as in Gobivenator (Tsuihiji et al., 2014) and Saurornithoides (Norell et al., 2009), but different from the posteriorly curved flange in Almas (Pei et al., 2017a). A prominent projection develops ventral to the pterygoid flange, as in the holotype $(X u, 2002)$. This projection is shorter than the pterygoid flange. Posteriorly, the pterygoid has an articular facet for the 
304 basipterygoid process of the basisphenoid, formed by a short medial process and the quadrate 305 ramus.

306 The quadrate ramus is shelf-like and bifurcates in medial view (Fig. 7C), as in

307 Sinornithosaurus (Xu \& Wu, 2001; Xu, 2002) and Archaeopteryx (Elzanowski \& Wellnhofer,

308 1996). The dorsal process is longer than the ventral process, and the dorsal margin of the dorsal

309 process is thickened. The quadrate ramus contacts the pterygoid ramus of the quadrate laterally.

310 The lateral surface of the quadrate ramus bears an oblique ridge and its medial surface is concave.

\section{Vomer}

Only the paired pterygoid rami of the vomers are preserved (Fig. 7), which extend posteriorly to the level of the last dentary tooth, and therefore it is impossible to determine the degree of the fusion of the vomers. The pterygoid ramus is a vertical plate as in Dromaeosaurus (Currie, 1995) and Archaeopteryx (Elzanowski \& Wellnhofer, 1996). The contact between the vomer and the pterygoid is seemingly akinetic because the suture between the two bones is hardly discernible, unlike the less tightly joined contact in Velociraptor(Barsbold \& Osmólska, 1999).

\section{Palatine}

The palatines are well preserved (Figs. 2, 3 and 7). As in other non-avian theropods, the palatine is tetraradiate and comprised of a vomeropterygoid process, a maxillary process, a jugal process and a pterygoid process. As in dromaeosaurids (Norell \& Makovicky, 2004), Gobivenator (see fig. 5 in Tsuihiji et al., 2014) and Archaeopteryx (Elanowski, 2001), the palatine forms the lateral 
325

326

327

328

329

330

331

332

333

334

335

336

337

338

339

340

341

342

343 345

344 The medial surface of the vomeropterygoid process is smooth, possibly for contacting with the

margin of the long pterygopalatine fenestra (Fig. 7). As in Archaeopteryx (Mayr et al., 2007;

Rauhut, Foth \& Tischlinger, 2018), an anterior triangular depression and a posterior sub-

triangular depression are formed on the main body of the palatine and are separated by a

prominent transverse crest that reaches the base of the jugal process (Fig. 3). This is

distinguished from that in Velociraptor (Barsbold \& Osmólska, 1999), Deinonychus (Ostrom,

1969), and Gobivenator (Tsuihiji et al., 2014), in which the transverse crest is absent. A canal

opens into the maxillary process at the anterior end of the anterior depression. Another canal

passes into the transverse crest at the anterodorsal end of the posterior depression, and terminates

at the posterodorsal end of the anterior depression.

In lateral view, the maxillary process is long and slender with an anterior upturning end,

forming the posterior and the lateral margins of the internal naris. This process is longer than the

vomeropterygoid process as in Gobivenator (Tsuihiji et al., 2014) and Archaeopteryx (Mayr et

al., 2007), but unlike the condition in Deinonychus (Ostrom, 1969) and Velociraptor (Barsbold

\& Osmólska, 1999), in which the process is shorter. A shallow lateroventral trough is developed

on the maxillary process, possibly for contacting the maxilla. This trough widens posteriorly, and is dorsally and posteriorly defined by a laterally directed lamina.

The vomeropterygoid process is dorsoventrally deep and anteriorly hooked, and it is vertically oriented (Figs. 7B and 7C), constituting the medial edge of the internal naris (Fig. 7A).

A prominent ridge of the vomeropterygoid process develops dorsally and twists posteromedially. other palatine. A small vertical shelf is present posterior to the smooth medial surface, and bears 
346 a sub-triangular depression. Ventral to this vertical shelf, a large groove is present along the

347 vomeropterygoid process and reaches the base of the pterygoid process.

348 The jugal process is short and sub-triangular, forming the anterolateral margin of the

349 palatine fenestra, just as in Gobivenator (Tsuihiji et al., 2014), Deinonychus (Ostrom, 1969),

350 Velociraptor (Barsbold \& Osmólska, 1999) and Archaeopteryx (Mayr et al., 2007). Posteriorly,

351 the jugal process contacts the jugal. The ventral surface of the jugal process is smooth.

352 The pterygoid process is twice as long as the vomeropterygoid process, extending

353 posteriorly for contacting with the pterygoid and the ectopterygoid, contributing to the medial

354 margin of the palatine fenestra (Fig. 7A). The anterior half of the pterygoid process is band-like

355 with a curved lateral border, but the posterior half of the pterygoid process widens posteriorly.

356

\section{Ectopterygoid}

358 The left ectopterygoid is preserved (Fig. 7). It consists of a jugal process, an ectopterygoid

359 (pterygoid) flange and a pterygoid process. The jugal process is hooked and contacts the medial

360 surface of the jugal below the orbital margin, as in other non-avian theropods. This process

361 sharpens posteriorly, and separates the palatine fenestra from the subtemporal fossa (Ostrom,

362 1969). The jugal process extends posteriorly almost to the level of the posterior end of the

363 pterygoid process, in contrast to Linhevenator (Xu et al., 2011) and Archaeopteryx (Elzanowski

$364 \&$ Wellnhofer, 1996) in which the process is distinctly shorter than the pterygoid process. The

365 medial portion of the jugal process is short, and therefore the space between the jugal process

366 and the pterygoid process is mediolaterally narrow, unlike Linhevenator (Xu et al., 2011), 
367 Jianianhualong (see fig. 2 in Xu et al., 2017) and Archaeopteryx (Elzanowski \& Wellnhofer,

368 1996) in which this space is large. The pterygoid flange is robust and extends posteroventrally. A

369 groove is present on the pterygoid flange in lateral view. Medial to the pterygoid flange, a deep

370 pocket excavates the ventral surface of the pterygoid process, as in other non-avian theropods.

371 The pterygoid process is horizontally oriented, overlapped by the pterygoid process of the

372 palatine, as in Archaeopteryx (Elzanowski \& Wellnhofer, 1996). The pterygoid process overlaps

373 the main body of the pterygoid immediately anterior to the quadrate ramus of the pterygoid. The

pterygoid process is wider than long as in Archaeopteryx (Elzanowski \& Wellnhofer, 1996).

Dorsally, a depression occupies most of the dorsal surface of the pterygoid process, and a ridge

separates a narrow and deep groove from the depression posteriorly, as in Linhevenator (Xu et al.,

2011), but unlike the condition in Dromaeosaurus (Currie, 1995), Velociraptor (Barsbold \&

Osmólska, 1999), and Tsaagan (Norell et al., 2006) in which such a depression is absent. This

condition is also different from Deinonychus (Ostrom, 1969) and Saurornitholestes (Sues, 1978)

in which a pit and two little depressions are present respectively. Interestingly, the dorsal

depression seems connecting the ventral pocket through some foramina like in Saurornitholestes

(Sues, 1978), though it is difficult to known whether this condition is a preservational artifact in

PMOL-AD00102.

\section{Epipterygoid}

The left epipterygoid is preserved (Figs. 2 and 7). This is the first report of an epipterygoid in 
388

389

390

391

392

393

394

395

396

397

398

399

400

401

402

403

404

405

406

407

408

other non-avian theropods. This bone is laterally visible through the orbit. The epipterygoid bears a shallow fossa on the medial surface that is anterodorsally bordered by a thickened ridge

(Fig. 7C). Medially, the epipterygoid overlaps the anterodorsal surface of the quadrate ramus of the pterygoid, unlike Dromaeosaurus in which the epipterygoid overlaps the dorsal rim of the quadrate ramus of the pterygoid (Colbert \& Russell, 1969). Dorsally, the epipterygoid has a pointed laterosphenoid process, and this process possibly contacts the laterosphenoid, inferred from a depression on the laterosphenoid.

\section{Frontal}

The left and right frontals are well-preserved. The posterolateral portion of the right frontal is partially fractured (Figs. 3 and 4A). The anteroposterior length of the frontal is $34.4 \mathrm{~mm}$, approximately three times of the minimum width between the orbits. This ratio is similar to that of Mei, but is larger than that in Jianianhualong (1.8 times; Xu et al, 2017).

The frontal is subtriangular in dorsal view and forms the dorsal margin of a large and circular orbit. The lateral margin of the frontal sharpens anteriorly (Fig. 8A). A slot is present on the anterolateral end of the frontal (Fig. 8) as seen in dromaeosaurids ( $X u \& W u, 2001)$. However, this slot is not for the lacrimal attachment in this specimen and only defined by a anterolateral prong, different from the condition in dromaeosaurids, in which the posterior process of the lacrimal is attached onto this slot (Currie, 1995). This anterolateral prong of the frontal possibly represents the vertical lamina in the holotype (Xu et al., 2002), and this variation is probably preservational. The orbital margin of the frontal is vaulted and rugose, as in other troodontids 
409 (Currie, 1985; Norell et al., 2009; Lü et al., 2010; Tsuihiji et al., 2014; Pei et al., 2017a) and

410 most dromaeosaurids (e.g., Currie, 1995; Norell et al., 2006; Xu et al., 2015a). Dorsally, a

411 shallow trough is developed lateral to the suture between the frontals, and a longitudinal ridge is

412 present along the midline of each frontal as in Zanabazar (Norell et al., 2009). A distinct

413 postorbital process diverges gently from the orbital rim (Fig. 4A), different from the sharp

414 emargination in dromaeosaurids (Currie, 1987a). The distal end of the postorbital process is

415 broadly notched between an anterior projection and a posterior projection (Fig. 4A). A

416 depression is present on the dorsal surface of the postorbital process, and possibly medially

417 continuous with the supratemporal fossa, like in Zanabazar (Norell et al., 2009), Troodon(Currie,

418 1985), Linhevenator (Xu et al., 2011) and some dromaeosaurids (e.g., Barsbold \& Osmólska,

$4191999 ; X u \& W u, 2001)$. The anterior margin of the supratemporal fossa is straight, defined by a

420 transverse ridge on the frontal that reaches onto the postorbital process (Fig. 4A), as in other

421 troodontids but in contrast with a sigmoidal boundary in dromaeosaurids (Norell \& Makovicky,

422 2004). Posterior to this ridge, the frontal slopes down gently, different from a steep slope in

423 Troodon (Currie, 1985) and Zanabazar (Norell et al., 2009). The frontal-parietal suture is

424 sigmoidal.

425 The crista cranii is well developed and observable in lateral and ventral views (Fig. 8). The

426 posterior portion of the crista cranii is deep and inclines medioventrally, whereas the anterior

427 portion is shallow and vertical. The crista cranii forms the lateral wall of the trough for the olfactory tract and olfactory bulb. This trough is shallow at the anteriormost part, and becomes 
429 deeper and wider posteriorly. A shallow shelf separates the left and right troughs along the 430 midline of the frontals (Fig. 8B).

431

432

Parietal

433 The parietals are fused as in other troodontids (Fig. 4A). The parietal is fused with the

434 supraoccipital posteriorly. The sagittal crest is high and lamina-like along the midline of the 435 parietals (Fig. 8A), as in Zanabazar and Troodon (Norell et al., 2009), in contrast to the 436 condition in the holotype (Xu et al., 2002), Jianianhualong (Xu et al., 2017), Liaoningvenator 437 (Shen et al., 2017b) and Linhevenator (Xu et al., 2011) where the crest is low, and distinct from Mei (Xu \& Norell, 2004) in which such a crest is absent. The dorsal surface of the parietal has a gentle slope lateral to the sagittal crest. In lateral view, the suture between the parietal and the laterosphenoid is roughly straight like that in the holotype $(X u, 2002)$. The nuchal crest (Fig. 8A) is well developed with a similar depth of the sagittal crest, but the nuchal crest is distinctly longer than the sagittal crest. The nuchal crest is slightly sigmoidal in dorsal view (Fig. 4A), defining the posterior boundary of the supratemporal fossa and the dorsal margin of the occiput.

\section{Braincase}

446 The occiput is well-preserved. The bones forming the occiput are fused, and the sutures between 447 the supraoccipital, the exoccipital and the basioccipital are not identifiable. The occiput inclines 448 slightly anteriorly as preserved in this specimen. The foramen magnum is larger than the 
450 other troodontids $(X u, 2002)$ and some dromaeosaurids (e.g., Tsaagan; Norell et al., 2006).

451 Dorsal to the foramen magnum, two foramina probably represent the openings for cerebral veins

452 (Fig. 9). The occipital condyle has a constricted neck (Fig. 8B) as in Troodon and Zanabazar

453 (Norell et al., 2009). Two foramina represent the openings of the CN XII immediately lateral to

454 the occipital condyle (Fig. 9). Lateral to the openings of CN XII, a larger foramen deriving from

455 the metotic strut represents the exit of CN X and CN XI (Fig. 9).

456 The exoccipital is fused with the opisthotic. The paroccipital process is short and distally

457 pendulous, as in $\mathrm{Mei}$ (Xu \&Norell, 2004), and extends lateroventrally. The distal end of the

458 paroccipital process is ventral to the level of the ventral margin of the occipital condyle. In

459 contrast, the paroccipital process is long, straight and extends laterally or posterolaterally in

460 dromaeosaurids (Turner, Makovicky \& Norell, 2012). The base of the paroccipital process is

461 constricted (Fig. 9) as in the holotype (Xu, 2002).

462 The basioccipital is complete. It is co-ossified with the basisphenoid-parasphenoid

463 anteriorly. Anterior to the occipital condyle, a subcondylar recess is developed in the

464 basioccipital (Fig. 8B) as in Anchiornis (Pei et al., 2017b). More anteriorly, two reduced basal

465 tubera are present, but seem confluent with each other by a septum (Fig. 9), unlike the holotype

466 and other troodontids in which a V-shaped notch is present between the two tubera $(X u, 2002)$.

467 The posterior surface of the basal tubera is concave, which is probably a homologous structure to

468 the V-shaped notch. This variation between PMOL-AD00102 and the holotype could be

469 preservation or ontogeny related. 
The basisphenoid is co-ossified with the parasphenoid anteriorly, and contacts the pterygoid

471

472

473

474

475

476

477

by two diverging basipterygoid processes. Unlike other troodontids, but similar to dromaeosaurids (Norell \& Makovicky, 2004), Anchiornis (Pei et al., 2017b) and Archaeopteryx (Rauhut, 2014), a basisphenoid recess is developed (Fig. 8B). Two fossae are present lateral to the posterior end of the basisphenoid recess (Fig. 8B). This represents a novel character that has not been reported in other troodontids. As in the holotype (Xu et al., 2002) and Liaoningvenator (Shen et al., 2017b), the basipterygoid process is solid and the basipterygoid recess is well developed on the dorsolateral surface of the basipterygoid process (Figs. 8 and 10). In contrast, the basipterygoid process in the Late Cretaceous troodontids is hollow, and the basipterygoid recess is absent (Turner, Makovicky \& Norell, 2012). The distal end of the basipterygoid process is blunt, unlike the pointed end in the holotype (Xu et al., 2002). As in the holotype (Xu, 2002), the basipterygoid process directs lateroventrally, but unlike the condition in Troodon, in which the process is relatively posteriorly directed (Currie \& Zhao, 1993).

The anterior end of the parasphenoid is posterior to the lacrimal as preserved in the specimen. As in Velociraptor (Barsbold \& Osmólska, 1999), the preserved anterior portion of the cultriform process is V-shaped in cross section. The base of the parasphenoid is not bulbous, as in the holotype (Xu et al., 2002), and the pituitary fossa is well preserved. Laterally, unlike the holotype $(X u, 2002)$, the otosphenoidal crest (Fig. 10) is developed and defines a "lateral depression" (parasphenoid recess; Xu, 2002) as in other troodontids (Makovicky \& Norell, 2004). As in Byronosaurus (Makovicky et al., 2003), the lateral depression is bordered posteriorly by the subotic recess. The parasphenoid recesses on both sides are large and highly pneumatized, 
491

492

493

494

495

496

497

498

499

500

501

502

503

504

505

506

507

508

509

510

511

and connect with each other medially. As in the holotype $(X u, 2002)$, the parasphenoid recess is divided into two openings by an ossified bar, for accommodating the pituitary fossa and the internal carotids (Fig. 10). The anterior opening is oval, and the posterior one (the anterior tympanic recess ) is dorsoventrally elongated. Ventral to the divergence of the two ossified carotid canals, a bar extends ventrally into the basisphenoid and this bar possibly represents a neomorph (Fig. 10).

The laterosphenoid is a relatively large bone forming the anterolateral wall of the braincase. The laterosphenoid is co-ossified with the orbitosphenoid and the basisphenoid-parasphenoid ventrally. As in Troodon (Currie, 1985), the postorbital process of the laterosphenoid contacts the frontal dorsally and has a smooth distal capitulum for contacting the postorbital. The laterosphenoid forms the lateral wall of the braincase and is almost vertical and smooth. A pit develops on the ventral surface of the laterosphenoid (Fig. 10) ventrally as in other troodontids (Makovicky et al., 2003). Medial to the pit, two foramina are present, representing the exits of CN IV and CN III respectively (Fig. 10). The exit for CN IV is higher than that of CN III. Posterior to the laterosphenoid, the prootic forms the posterolateral wall of the braincase.

The prootic is co-ossified with the basisphenoid ventrally and the opisthotic posteriorly. There is a ridge defining the anterior margin of the dorsal tympanic recess on the suture between the prootic and the laterosphenoid. As in the holotype (Xu et al., 2002), the dorsal tympanic recess is a large and shallow depression (Figs. 8A and 10). Anteroventral to the dorsal tympanic recess, two openings are separated from each other by a mound as in Troodon (Norell, Makovicky \& Clark, 2000). The anterior one of these two openings represents the exit of CN V and the 
512 posterior one represents the exit of CN VII (Fig. 10). As in Byronosaurus and Almas (Norell,

513 Makovicky \& Clark, 2000; Pei et al., 2017b), CN VII and the middle ear cavity are located

514 dorsal to the rim of the lateral depression (Fig. 10), but in contrast to the condition in Zanabazar 515 and Saurornithoides (Norell et al., 2009), in which CN VII and the middle ear cavity are located 516 within the lateral depression. As in the holotype $(X u, 2002)$ and Troodon (Turner, Makovicky \& 517 Norell, 2012), the fenestra ovalis and the fenestra pseudorotunda are separated from each other 518 by the crista interfenestralis which is depressed within the middle ear cavity (Fig. 10), different 519 from Byronosaurus in which the crista interfenestralis is flush with the lateral surface of the prootic (Makovicky et al., 2003). Posterior to the fenestra pseudorotunda, the metotic fissure penetrates the lateral wall of the braincase (Fig. 10) as in Troodon (Currie \& Zhao, 1993), Byronosaurus (Makovicky et al., 2003), and the unnamed troodontid IGM 100/44 (Barsbold, Osmólska \& Kurzanov, 1987). As in Byronosaurus (Makovicky et al., 2003), the hypoglossal nerve possibly emerges from the braincase through this fissure. As in Byronosaurus (Makovicky et al., 2003), a small foramen is developed on the anterior wall of the metotic fissure at the midheight (Fig. 10) and is possibly the opening of the perilymphatic duct (Makovicky \& Norell, 1998). Dorsal to the metotic fissure, the accessory tympanic recess is present (Fig. 10). As in the holotype $(X u, 2002)$, the caudal tympanic recess is seemingly confluent with the accessory tympanic recess through a shallow groove. sutures are undetectable as the bones forming the braincase are co-ossified as mentioned above. 
533 for accommodating the optic lobe (Fig. 11A). Posterior to the fossa, a groove represents the

534 passage for the middle cerebral vein that emerges posteriorly from the braincase through its

535 posterior canal (Fig. 11A). Ventral to the groove, the floccular recess is large and deep (Figs.

$53611 \mathrm{~A}$ and 11B). An inner opening for CN VII is present ventral to the floccular recess. A large

537 opening represents the exit of CN V anterior to CN VII (Fig. 11B). Posteroventral to the

538 floccular recess, two foramina are developed on the medial wall of the inner ear (Fig. 11B). The

539 dorsal foramen is smaller, possibly represents the endolymphatic duct. The ventral foramen is

540 larger and is divided into two foramina entering the inner ear as the opening for CN VIII. The

541 upper foramen and the lower foramen are for the vestibule branch and cochlear branch of $\mathrm{CN}$

542 VIII respectively. Posterior to the CN VIII, a small foramen is present as the perilymphatic duct

543 (Fig. 11B). Further posteriorly, as in Byronosaurus (Makovicky et al., 2003), the metotic fissure

544 shows an hourglass shape and has a constriction slightly below its midheight (Fig. 11B). Further

545 posterior to the metotic fissure, two openings for CN XII are present and the upper one is larger

546 than the lower one (Fig. 11B).

547

\section{Stapes}

549 The left stapes is preserved, represented by a proximal shaft and a footplate (Fig. 12). The stapes

550 is reported in troodontids for the first time. As in tyrannosaurids (Witmer \& Ridgely, 2009) and

551 oviraptorids (Clark, Norell \& Rowe, 2002), no groove is present in the paroccipital process to

552 receive the stapes in PMOL-AD00102, but in contrast to the condition in dromaeosaurids

553 (Colbert \& Ostrom, 1958; Currie, 1995) in which such a groove is present. The stapes is a 
554 slender bone with a small footplate fitting the shape of the fenestra ovalis. The stapes projects

555 both posterolaterally and ventrally, as in tyrannosaurids (Witmer \& Ridgely, 2009) and

556 oviraptorids (Clark, Norell \& Rowe, 2002) but unlike the posterolaterally directed condition in

557 dromaeosaurids (Colbert \& Ostrom, 1958).

558 The footplate is subtriangular (Fig. 12A), and its maximum diameter is about $1.7 \mathrm{~mm}$. The

559 maximum diameter of the footplate is about four times the diameter of the shaft (Fig. 12A). The

560 shaft of the stapes is cylindrical, and it attaches laterally on the footplate, at a position slightly

561 anteroventral to the midpoint of the footplate (Fig. 12A). The shaft is almost vertical to the

562 footplate, and is only slightly posteriorly oblique (Fig. 12B). A small bar medial to the medial

563 condyle of the left quadrate is recognized as the distal portion of the stapes, as inferred from its

564 slender shape (Fig. 4B). If this interpretation is correct, the stapes has a tapering distal end.

565

566 MANDibLe

567 Both mandibular rami are well-preserved at the middle-posterior portion (Fig. 13). The dorsal

568 margin of the post-dentary portion of the mandibular ramus is nearly straight in lateral view,

569 while the ventral margin is slightly bowed. The external mandibular fenestra is large and

570 elongated with a length of $28 \mathrm{~mm}$ (Fig. 13A), as in Saurornithoides (Osborn, 1924),

571 Sinornithoides (Russell \& Dong, 1993), Gobivenator (Tsuihiji et al., 2014), Velociraptor

572 (Barsbold \& Osmólska, 1999), Microraptor (Pei et al., 2014) and Tsaagan (Turner, Makovicky

$573 \&$ Norell, 2012), in contrast to a small condition in Deinonychus (Ostrom, 1969) and 
Dentary

577 Both dentaries are preserved with the posterior end that bears the last four teeth (Fig. 13). As in

Urbacodon (Alexander \& Sues, 2007), the labial side of the alveoli is higher than the lingual side

579 (Fig. 13E). The dentary bears a lateral groove as in other troodontids (Makovicky \& Norell,

2004). As in Daliansaurus (Shen et al., 2017a), this dentary groove reaches the posterior end of

the dentary. The posteroventral portion of the dentary is deep and sheet-like. The

intramandibular process of the dentary is partially preserved and overlaps the anterodorsal

surface of the anterior process of the surangular (Figs. 13A and 13D). At the ventral part of the

intramandibular process, a small prong articulates dorsally with the small ventral groove of the

anterior process of the surangular. The posteroventral part of the dentary overlaps the smooth

lateral surface of the anterodorsal ramus of the angular with a broad, oblique suture. Medially,

the dentary is overlapped by the splenial and the supradentary. A deep meckelian fossa is present

between the dentary and the splenial. A deep socket for accommodating the surangular lies dorsal to the meckelian fossa.

\section{Angular}

Both angulars are nearly completely preserved (Fig. 13). The angular is bow-like, forming most

of the ventral margin of the mandible posterior to the dentary. It forms the anterior and ventral 
596 posteroventral part of the dentary and the splenial. Laterally, the angular extends posteriorly to 597 the level of the surangular foramen and overlaps the surangular along a nearly straight suture 598 posterior to the external mandibular fenestra (Figs. 2 and 13A). Medially, the angular forms the 599 ventral border of the mandibular fossa, with the lateral wall slightly higher than the medial wall 600 (Figs. 13C and 13E).

601

602

Surangular

603

The left and right surangulars are nearly completely preserved (Fig. 13). The surangular forms

604 most of the dorsal margin of the mandible posterior to the dentary. Anteriorly, the surangular is straight and blade-like, and forms the dorsal border of the external mandibular fenestra. Its anterior end is blunt and wedged between the dentary and the coronoid. At the level of the midpoint of the external mandibular fenestra, a small anterior surangular foramen opens laterally, and extends as a groove anteriorly (Fig. 13A). Posterior to the foramen, the surangular is laterally swollen. The surangular becomes dorsoventrally deep posterior to the external mandibular fenestra, about twice as deep as the anterior portion and has a well-developed laterodorsal ridge. Medial to the laterodorsal ridge, a flat medial shelf of the surangular forms the dorsal border of the adductor fossa, making the cross section of the surangular ' $T$ '-shaped (Fig. 13F) as in the holotype (Xu, 2002; Xu et al., 2002), which is also a diagnostic feature of Sinovenator changii.

614 Ventral to this laterodorsal ridge, a prominent surangular foramen is present laterally (Figs. 13A and 13D). Its diameter is about $30 \%$ of the depth of the posterior surangular, relatively larger 
616 than that in the holotype $(X u, 2002)$ and Gobivenator (Tsuihiji et al., 2014). The surangular is

617 overlapped by the angular along a longitudinal suture ventrally.

618

619 Articular

620 Both articulars are preserved. The articular is semi-co-ossified with the prearticular medially and

621 the surangular laterally. It bears two fossae that are separated by a rounded anteromedially-

622 oriented ridge (Fig. 13B) to accommodate the quadrate condyles. The lateral fossa is shallower

623 than the medial one. The mandibular fossae are more ventrally positioned than the dorsal margin

624 of the mandible. Dorsally, the stout retroarticular process is sculptured by a transverse and deep

625 groove anteriorly. This groove is probably for the attachment of the depressor mandibulae

626 muscle, unlike Gobivenator in which this attachment is represented by a broadly concave surface

627 (Tsuihiji et al., 2014). On the posteromedial margin of the retroarticular process, a vertical

628 columnar process (Figs. 13B and 13C) is present as in dromaeosaurids (Currie, 1995).

629

630

\section{Prearticular}

631 The right prearticular is more completely preserved than the left one at the medial side of the

632 postdentary portion (Fig. 13E). Anteriorly, the prearticular is deep and sheet-like, and forms the

633 medial wall of the mandibular adductor fossa with the coronoid and the splenial. Anteroventrally,

634 the prearticular encloses the internal mandibular fenestra with the angular (Fig. 13E). The

635 internal mandibular fenestra is roughly crescentic, unlike the sub-rectangular internal mandibular

636 fenestra in Dromaeosaurus (see fig. 7E in Currie, 1995). Posterior to the internal mandibular 
637 fenestra, the ventral surface of the prearticular becomes mediolaterally wide and forms most of

638 the ventral margin of the adductor fossa (Fig. 13C). More ventrally, the prearticular articulates

639 with the angular. Posterolaterally, a trough is developed, and gradually slopes posteriorly. This

640 trough is dorsally defined by a bony sheet whose anterior portion directs lateroventrally and the

641 posterior portion directs laterodorsally. Medially, the prearticular overlaps the medial surface of

642 the articular.

643

644 Splenial

645 Both splenials are partially preserved. The splenial anterior to the level of the last third dentary

646 tooth is missing. The posterior margin of the splenial is forked on the medial side (Fig. 13E), but

647 the posterodorsal branch of the left splenial is damaged (Fig. 13C). The posterodorsal branch gradually slopes down and contacts the medial surface of the coronoid and the prearticular. The posteroventral branch wraps the medial and ventral surfaces of the angular, and is laterally exposed as a broad triangle, as in other deinonychosaurians (Currie, 1995). Anterior to the contact with the angular, the splenial is shelf-like, and contacts the medial surface of dentary.

\section{Coronoid and supradentary}

The coronoid and the supradentary are preserved in PMOL-AD00102 (Fig. 13). In medial view, the strap-like supradentary overlaps the dentary immediately ventral to the alveolar margin. As in other non-avian theropods (Currie, 2003), the supradentary is co-ossified with the coronoid posteriorly. The coronoid is shelf-like and more than four times as deep as the supradentary (Fig. 
658 13C). The ventral and dorsal margins of the coronoid are nearly parallel and the posterior half of 659 the coronoid is concave medially. The posterior margin of the coronoid is bifurcated, forming the 660 anterodorsal margin of the addcutor fossa (Fig. 13E). The dorsal process is slightly longer than 661 the ventral one.

662

663

\section{DENTITION}

Only the roots of the last two maxillary teeth are preserved on the left maxilla. The maxillary tooth row reaches close to the posterior end of the maxilla, like in other Jehol troodontids but different from Late Cretaceous troodontids.

The last four dentary teeth are preserved in each dentary (Fig. 13). The anterior two of these teeth are preserved with their crowns, and the last two teeth are nearly complete and located in alveoli. The alveoli are separated by a septa. The teeth are mediolaterally compressed. The crown curves posteriorly and its lateral and medial surfaces are flat. The medial carina is smooth, while the distal carina is serrated, as in the holotype (Xu, 2002), Sinusonasus (Xu \& Wang, 2004),

Daliansaurus (Shen et al., 2017a), Liaoningvenator (Shen et al., 2017b), Jianianhualong (Xu et al., 2017), Troodon (Currie, 1987b), Linhevenator (Xu et al., 2011), Sinornithoides (Currie \& Dong, 2001), Saurornithoides and Zanabazar (Norell et al., 2009), in contrast to Xixiasaurus (Lü et al., 2010), Jinfengopteryx (Ji \& Ji, 2007), Byronosaurus (Norell, Makovicky \& Clark, 2000), Gobivenator (Tsuihiji et al., 2014), Almas (Pei et al., 2017a) and Urbacodon (Alexander \& Sues,

677 2007), in which all teeth are unserrated. As in other troodontids (Makovicky \& Norell, 2004), a constriction exists between the tooth crown and root. 
679 On the right dentary, the third tooth from the last seems to be the largest among the 680 preserved teeth with a height of the crown up to $3.7 \mathrm{~mm}$. The second last alveolus bears a small 681 replacement tooth that only has the crown tip exposed medially (Figs. 13C and 13E). The crown 682 of the last tooth is half as high as its root.

\section{CERVICAL VERTEBRAE}

The paired proatlases and the anterior six cervical vertebrae are preserved in articulation (Fig.

14). The neural spines of the post-axis cervical vertebrae are broken more or less. The sixth

cervical vertebra is only preserved with two prezygapophyses. The neural arch and the centrum are fused in post-atlas cervical vertebrae, implying that PMOL-AD00102 is an adult individual.

\section{Proatlas}

Both proatlas are well preserved in this specimen (Figs. 3 and 14). The proatlas is comprised of a main body and a posterior process. The posteroventral margin of the proatlas is curved (Fig. 15E). Medially, the proatlas has a concave surface (Fig. 15F). In lateral view, the main body is triangular and possibly articulates with the exoccipital anteriorly in life. The posterior process is thicker than the main body and is attached on the atlantal vertebral arch. The proatlas has only been reported in Gobivenator (Tsuihiji et al., 2014) among troodontids, but commonly exists in amniotes.

\section{Atlas}


699 The atlas is comprised of a centrum, an intercentrum and two neural arches. The atlantal arches

700 and intercentrum are not fused in this specimen, as in dromaeosaurids and Aves (Norell \&

701 Makovicky, 2004). The atlantal centrum, namely odontoid, is co-ossified with the axis (Fig. 15I).

702 The odontoid contacts the occipital condyle anteriorly and is positioned on the dorsal surface of

703 the atlantal intercentrum. The odontoid is sub-coniform and wider than high in anterior view.

704 The atlantal intercentrum is U-shaped in anterior view (Fig. 15A). Anteroventral to the

705 anterior end of the odontoid, a fossa defined by a septa on the intercentrum is developed to

706 accommodate the occipital condyle (Fig. 15B). As in other non-avian theropods, this structure

707 allows the skull to mobile up and down (Sereno \& Novas, 1993). The articular surface with the

708 atlantal arch on the atlantal intercentrum faces anteroventrally (Fig. 15C). The lateral edge of the

709 posterior surface of the atlantal intercentrum is marked by a lip-like margin that is for the

710 attachment of the capsular ligament as in Deinonychus (Ostrom, 1969). Ventrally, a facet on the

711 posteroventral atlantal intercentrum is present, possibly for contacting the single-headed atlantal

712 rib (Fig. 15D).

713 The paired neural arches are not co-ossified. The atlantal neural arch is triradiate with a stout

714 postzygopophysis that articulates the lateral surface of the axis (Fig. 14). The epipophysis is

715 present lateral to the zygopophyseal facet (Figs. 15G and 15H). At the base of each neural arch,

716 the pedicle is slightly expanded in lateral view (Fig. 15G). The ampullae is tab-like and curves

717 medially (Fig. 15G). 
720 The axis is completely preserved, but broken into two parts (Fig. 14). The anterior part was

721 scanned by CT with the skull and mandibles, as seen in Figure 15I. The posterior part and the

722 succeeding postaxial cervicals are shown in Figure 14. The axis is well ossified, lacking the

723 suture of the neural arch and the centrum. Anteriorly, the axis is co-ossified with the atlantal

724 centrum as a well developed odontoid (Fig. 15I). Similarly, the axial intercentrum is co-ossified

725 at the anteroventral corner of the axis. The intercentrum is short, about one fifth of the centrum

726 in length. The intercentrum inclines anteroventrally, and forms a concavity for the atlantal

727 intercentrum. This articulated structure is possibly functional for the lateral movement and

728 rotation of the skull (Sereno \& Novas, 1993).

729 The axial centrum is compressed bilaterally, and marked by two pleurocoels on each side

730 (Fig. 14). The larger pleurocoel is centrally positioned, while the smaller one is dorsal to the

731 former. Posteriorly, the centrum extends slightly beyond the neural arch, different from the

732 condition in dromaeosaurids (Turner, Makovicky \& Norell, 2012). The diapophysis and

733 parapophysis are obscure by a slender axial rib that is preserved in articulation (Fig. 15I).

734 Dorsally, the neural arch has a large neural spine. The neural spine is blade-like, and roughly

735 triangular in lateral view. The dorsal margin of the neural spine is oblique posteriorly, and the

736 posterior edge of the neural spine is almost vertical. Unlike Jianianhualong (Xu et al., 2017), the

737 neural spine doesn't have a strongly posterodorsal expansion. Anteriorly, the prezygapophysis is

738 small and extends anteroventrally beyond the odontoidal base slightly, as in Deinonychus

739 (Ostrom, 1969). The postzygopophysis faces posteroventrally. The epipophysis is well developed

740 (Fig. 14), nearly overlapping the entire postzygapophysis as in Byronosaurus (Norell, Makovicky 
$741 \&$ Clark, 2000). Posteriorly, the epipophysis is not beyond the postzygapophysis, contrary to the

742 condition in some dromaeosaurids (Norell et al., 2006).

743

744

745 Postaxial cervical vertebrae

746 Four postaxial cervical vertebrae are preserved in articulation (Fig. 14). The articular facet

747 between the adjacent cervical vertebrae inclines anteriorly, as in Oviraptorosauria and other

748 Paraves (Turner, Makovicky \& Norell, 2012). These vertebrae are comparable in size. The

749 centrum extends posteriorly beyond the posterior margin of the neural arch, different from

750 dromaeosaurids in which the centrum does not extend beyond the posterior end of neural arch

751 (Turner, Makovicky \& Norell, 2012). Dorsally, the centrum is fused with the neural arch. The

752 sizes of the diapophysis and the prezygapophysis appear to increase gradually in the succeeding

753 vertebrae. In contrast, the size of the epipophysis reduces posteriorly along the cervical series

754 (Fig. 14).

755 The lateral surface of the third cervical vertebra is marked by two pleurocoels and a deep

756 depression (Fig. 14). These two pleurocoels are located posteroventral and posterior to the

757 diapophysis respectively. A deep depression is positioned more posteroventrally than the

pleurocoels. The diapophysis and parapophysis are well separated (Fig. 14). The diapophysis is

759 slender with a tongue-like shape in dorsolateral view. The articular facet of the diapophysis is

760 smaller than that of the parapophysis. The articular facet of the prezygapophysis slopes

anteroventrally. The postzygapophysis extends more laterally than posteriorly in dorsal view. 


\section{Cervical ribs}

764 Two atlantal ribs, firstly reported in troodontids, are partially preserved lateroventral to the axial centrum in PMOL-AD00102. The atlantal rib is single-headed and curves ventrally (Fig. 15I), as in Archaeopteryx (Tsuihiji, 2017). The axial rib is more robust than the atlantal rib (Fig. 15I). The third cervical ribs are associated with the third cervical vertebra (Fig. 14). They are slender, and longer than the corresponding cervical centrum. The fourth and fifth ribs become more robust than the anterior cervical ribs,.

\section{PHYLOGENETIC ANALYSIS}

In this study, we supplemented the phylogenetic dataset for coelurosaurians published by Xu et

al. (2015b) with new anatomical information of PMOL-AD00102 and Sinusonasus. Two separate phylogenetic analyses were conducted. We treated PMOL-AD00102 as an independent terminal in the first analysis (92 terminals, 374 characters), and merged new codings of PMOLAD00102 into the existing Sinovenator changii terminal in the second analyses (91 terminals, 374 characters). We added one additional state each for Character 6 and Character 8 to reflect the intermediate state of the subotic recess and the pneumatic lateral depression in IVPP V12615 and PMOL-AD00102 (see in the discussion section and the appendix for details). Phylogenetic analyses were performed with T.N.T. (Version 1.5; Goloboff, Farris \& Nixon, 2015). Each analysis was run using the traditional search strategy with 1000 replications, TBR and holding 10 trees per replication. 
$784(\mathrm{CI}=0.317, \mathrm{RI}=0.739)$. In the strict consensus topology, Mei was recovered as the basalmost troodontid, and PMOL-AD00102 was recovered in a polytomy with Sinovenator, Sinusonasus and the clade of other troodontids (Fig. 16A). This result does not recover PMOL-AD00102 and the original Sinovenator changii terminal as sister-group, because the dataset does not sample autapomorphies of Sinovenator changii (i.e., synapomorphies of IVPP V12615 and PMOLAD00102). However, this analysis does recover PMOL-AD00102, Sinovenator and Sinusonasus at a similar "evolutionary stage" as we expected. To investigate the exact relationships of Jehol troodonitds requires a comprehensive and careful study of each taxon such as Sinovenator, Mei, beyond the scope of this study.

After merging new codings of PMOL-AD00102 into the existing Sinovenator changii $=0.739)$. In the strict consensus topology, Mei was recovered as the basalmost troodontid while

Sinovenator was recovered as the second basalmost troodontid that is more derived than Mei but 
804 A. Identification of PMOL-AD00102 as Sinovenator changii and comparisons with other 805 Jehol troodontids.

806 PMOL-AD00102 can be assigned to the Troodontidae based on the combination of individual 807 characters that are typical of troodontids and/or have been regarded as synapomorphies for

808 809 troodontids in different studies (e.g., Makovicky \& Norell, 2004; Xu et al., 2017): a row of foramina along a longtitudinal line on the nasal; a well-developed supraorbital crest that expands laterally anterodorsal to the orbit on the lacrimal; a lateral ridge close to the ventral edge of the jugal; a pit on the ventral surface of the laterosphenoid; a reduced basal tubera that lie directly ventral to the occipital condyle; an oval-shaped foramen magnum; the quadrate bears a pneumatic fenestra and a lateral groove on the dentary. We refer PMOL-AD00102 to Sinovenator changii based on the presence of a surangular with a "T"-shaped cross-section, even though our phylogenentic analysis does not resolve the relationships between PMOL-AD00102 and other specimens of Sinovenator changii, due to the lack of Sinovenator changii autapomorphies in the phylogenetic dataset. This diagnostic feature of Sinovenator changii ("T"-shaped cross-section of the surangular) was not reported in other newly discovered troodontid specimens and therefore supports the affiliation of PMOLAD00102 to Sinovenator changii.

Another diagnostic feature suggested for Sinovenator changii (Xu et al., 2002), the antorbital fenestra with a vertical anterior margin is also present in the new specimen PMOLAD00102. However, this feature alone could not refer PMOL-AD00102 to Sinovenator changii because a vertical anterior margin is also found in the antorbital fenestra of Sinusonasus. 
in several other features: the frontal without the vertical lamina bordering the lacrimal, the

presence of a septum between the basal tubera, the presence of a basisphenoid recess, a deep sagittal crest and the basipterygoid process with a blunt distal end. It is difficult to ascertain whether these differences are allometric, ontogenetic or preservational. The variation on the frontal-lacrimal contact is possibly preservational and the variation on the basal tubera could be preservational or ontogenetic, as we mentioned earlier in the description section. The variations of the basisphenoid recess and the distal end of the basipterygoid process could also be preservational, given the fragmentary nature of the holotype. The difference between the deep sagittal crest in PMOL-AD00102 and the shallow sagittal crest in the holotype could either be preservational considering the fragmentary parietal of the holotype, or be ontogenetic considering the sizes of both specimens. Regardless of these variations, we still attribute PMOL-

AD00102 to Sinovenator changii instead of erecting a new taxon or attributing it to other existing troodontid taxa, until more fossil materials are available or more comprehensive studies are conducted.

Six other troodontids have been erected in the Jehol Biota: Mei, Sinusonasus,

Jinfengopteryx, Daliansaurus, Liaoningvenator and Jianianhualong. Within these Jehol troodontids, the dentary teeth of Jinfengopteryx completely lack serrations ( $J i \& J i, 2007)$. In contrast, other Jehol troodontids (except for $\mathrm{Mei}$, unknown to the dentary teeth) including 
846 dorsally articulated with the surangular. PMOL-AD00102 differs from $\mathrm{Mei}$ (see figs. 2a and 2b

847 in Xu \& Norell, 2004) and Sinusonasus (see figs. 1 and 2 in Xu \& Wang, 2004) by possessing the

848 lacrimal with a bifurcated posterior process. PMOL-AD00102 also differs from $\mathrm{Mei}(\mathrm{Xu} \&$

849 Norell, 2004), Liaoningvenator (Shen et al., 2017b) and Jianianhualong (Xu et al., 2017) by the

850 presence of a notched postorbital process of the frontal and a high and lamina-like saggital crest.

851 PMOL-AD00102 can also be distinguished from Jianianhualong (Xu et al., 2017) by the

852 presence of a mediolaterally narrow space between the jugal process and the pterygoid process of

853 the ectopterygoid, the presence of an anterior surangular foramen, the surangular lacking a

854 distinct fossa on its dorsal surface closed to its posterior end, the splenial with a forked posterior

855 margin and the posterodorsal portion of the axial neural spine without a distinct posterior

856 expansion.

857

858

\section{B. Braincase of PMOL-AD00102 and Sinovenator changii}

859

860

861

862

863

864

865

866
Sinovenator changii is the first troodontid reported from the Jehol Biota, and it was regarded as

the most basal troodontid that has intermediate morphologies linking the two branches of

deinonychosaurians: troodontids and dromaeosaurids (Xu et al., 2002). Sinovenator has typical

deinonychosaurian features that are also observed in dromaeosaurids but absent from more

derived non-Jehol troodontids, such as the non-arctometatarsalian pes, the opisthopubic

condition of the pelvis, etc. Among these deinonychosaurian features, a primitive profile of the

braincase (e.g., absence of the lateral depression, absence of the subotic recess, etc.) was

suggested as key evidence that sets Sinovenator changii aside from more derived troodontids, in 
867 which the braincase has a well-defined lateral depression and a fully developed subotic recess.

868 Although later reported troodontids from the Jehol Biota (Mei, Jinfengopteryx, Sinusonasus,

869 Jianianhualong, Daliansaurus and Liaoningvenator) are also considered relatively primitive

870 compared with their Late Cretaceous kins, no detailed morphologies of the braincase have ever

871 been reported to prove/disprove this primitive condition of the braincase in Sinovenator and/or

872 other Jehol troodontids. PMOL-AD00102, however, has a well-preserved cranial skeleton and

873 provides a rare opportunity to investigate the early evolutionary trend of these morphologies in

874 the troodontid braincase. Unlike reported in IVPP V12615, the new specimen PMOL-AD00102

875 shows a clear presence of the subotic recess, the otosphenoidal crest and basisphenoid recess.

The subotic recess is incipient in PMOL-AD00102 as a shallow depression, unlike the deep and clearly defined recess in Saurornithoides, Zanabazar, Troodon, and Byronosaurus. Although a typical subotic recess was not reported from the holotype of Sinovenator changii, that specimen (IVPP V12615) does have a lateroventrally faced depression lateroventral to the mid ear cavity and posterodorsal to the basipterygoid process (see fig. $1 \mathrm{~b}$ in $X u$ et al., 2002). This depression is located at the same position of the subotic recess of PMOL-AD00102 and derived troodontids. In contrast, such a structure is absent in dromaeosaurids and avialans (e.g. Norell et al., 2006). Here we regard these structures are homologous in IVPP V12615, PMOL-AD00102 and more derived troodontids, and the shallow subotic depression (incipient subotic recess) in Sinovenator represents an initial stage of the well developed subotic recess in more derived troodontids. 

subotic recess) on the lateral side of the braincase in Troodon, Saurornithoides and Zanabazar. The otosphenoidal crest in PMOL-AD00102 is more similar to that in Byronosaurus and Almas, in which the crest is positioned ventral to the opening for the facial nerve (CN VII) and dorsal to the anterior tympanic recess. A homologous structure also seems present in the braincase of IVPP V12615, at the same position between CN VII and the anterior tympanic recess (see fig. 1b in Xu et al., 2002). This structure of IVPP V12615 seems more smooth and shorter than the otosphenoidal crest in PMOL-AD00102, but this difference is possibly preservational, as the braincase of IVPP V12615 undergoes a slight deformation and somewhat erosion. Therefore, we regard both PMOL-AD00102 and IVPP V12615 has an otosphenoidal crest that is not as developed as in Troodon, Saurornithoides and Zanabazar. The lateral depression defined by the otosphenoidal crest in these two specimens is not as developed as in Troodon, Saurornithoides and Zanabazar, either, but it resembles that in Byronosaurus and Almas, in which the mid ear region and CN VII fall outside of the lateral depression. Notably, the otosphenoidal crest in

Sinovenator, Byronosaurus and Almas may be homologous to another curved ridge in

Saurornithoides between CN VII and the anterior tympanic recess (see fig. 11A in Norell et al., 2009). This curved ridge is ventral to the otosphenoidal crest in Saurornithoides, and therefore whether the so-called otosphenoidal crest in Sinovenator, Byronosaurus and Almas is 
907 homologous to that in Troodon, Saurornithoides and Zanabazar is unclear and needs more 908 careful investigations.

909 The basisphenoid recess is a primitive character in coelurosaurians, and is observed in 910 dromaeosaurids, Archaeopteryx and Anchiornis (Turner, Makovicky \& Norell, 2012; Rauhut, 911 2013; Pei et al., 2017b). But the basisphenoid recess was thought to be lost in troodontids 912 (Makovicky \& Norell, 2004). Presence of the basisphenoid recess in the new specimen indicates 913 that this morphology is possibly plesiomorphic in troodontids (at least present in the basal 914 members, such as Sinovenator). In addition, the weakly-developed basisphenoid recess in 915 Sinovenator possibly represents the initial stage of losing this recess in derived troodontids. 916 As discussed above, the braincase of Sinovenator is not as primitive as previously thought 917 to be, although it still shows an intermediate profile between derived troodontids and non918 troodontid paravians.

\section{Notable new morphologies observed in PMOL-AD00102}

Dromaeosaurids are characterized by the inverted "T"-shaped quadratojugal that contacts the

lateral process and mandibular condyle of the quadrate and defines a large quadrate foramen

(Norell et al., 2006). As a contrast, the quadratojugal is L-shaped and the quadrate does not have

a lateral process in troodontids, and these features are regarded as plesiomorphies in nondromaeosaurid paravians such as troodontids. However, because of the sparseness of wellpreserved or well-exposed materials in troodontids, how exactly the quadratojugal articulates with the quadrate is unclear in this family. Fortunately, the quadratojugal and quadrate are well 
928

929

930

931

932

933

934

935

936

937

938

939

940

941

942

943

944

945

946

947

948

preserved in PMOL-AD00102, providing a rare opportunity to decipher the articulation of these two bones. The main body of the quadratojugal in PMOL-AD00102 overlaps the lateral surface of the lateral condyle of the quadrate as observed in Gobivenator (see figs. 3a and 3c in Tsuihiji et al., 2014), and the squamosal process of the quadratojugal in PMOL-AD00102 wraps the posterior surface of the quadrate as in Sinornithoides (Russell \& Dong, 1993). The quadratojugal wraps the lateral and the posterior surfaces of the quadrate in troodontids, unlike the condition in oviraptorids and dromaeosaurids in which the quadratojugal is articulated with the quadrate only on the lateral side (Osmólska, Currie \& Barsbold, 2004; Norell et al., 2006). Thus, this quadrate-quadratojugal articulation in troodontids is different from that in oviraptorids and dromaeosaurids, and probably represents an apomorphy related to the feeding styles in the Troodontidae.

The stapes is a delicate bone, and rarely preserved in non-avian coelurosaurians. To date, the stapes was only found in dromaeosaurids, oviraptorids and tyrannosaurids (Colbert \& Ostrom, 1958; Clark, Norell \& Rowe, 2002; Witmer \& Ridgely, 2009), but the stapes in these findings are either incomplete or have only been briefly mentioned. Here, as the first report in troodontids, the stapes of PMOL-AD00102 are well revealed by using the CT-scan technique. The stapes of PMOL-AD00102 directs both posterolaterally and ventrally, and positioned outside a groove in the paroccipital process, as in tyrannosaurids and oviraptorids, but in contrast to the posterolaterally directed stapes that hosted in a groove along the paroccipital process in dromaeosaurids. Therefore, PMOL-AD00102 seems to have a conservative way of structuring the otic bone like in more primitive coelurosaurians but unlike the more closely related 
949 dromaeosaurids. In addition, the stapes in PMOL-AD00102 firstly reveals some new

950 morphological information on the ear of non-avian coelurosaurians, such as the subtriangular

951 footplate and the posteriorly inclined stapedial shaft. As far as we know among dinosaurians, the

952 shape of the footplate is nearly square in Allosauroidea (Madsen, 1976), semicircular in

953 Sauropodomorpha (Chapelle \& Choiniere, 2018) and unknown in Ornithischia. Therefore, even

954 though the stapes is commonly present in dinosaurians, the morphology of the footplate varies in 955 different lineages.

956 The epipterygoid was hypothesized to be lost in all troodontids by Tsuihiji et al. (2014)

957 based on a previous study of Gobivenator. However, our observation with the new specimen

958 shows the epipterygoid is actually present in Sinovenator, as firstly reported in the Troodontidae.

959 This implies that the loss of the epipterygoid is likely a derived character that present in later

960 diverging taxa of the family. Moreover, this finding supports the hypothesis that the loss of the

961 epipterygoid is possibly homoplastic in derived troodontids and avialans (except for

962 Archaeopteryx) (Tsuihiji et al., 2014).

963

The atlantal ribs have never been reported in troodontids due to the rare preservation of the

964 elements. The atlantal ribs are well preserved in PMOL-AD00102 and have a slender shape,

which supports the hypothesis that the atlantal rib has an evolutionary trend to reduce the size

966 along the theropod lineage (Tsuihiji, 2017). Additionally, the troodontid atlantal rib curves

967 ventrally as in basal birds (Tsuihiji, 2017), unlike the straight condition in dromaeosaurids (see

968 fig. 2 in $X u$ et al., 2010). 
that have not been noticed or rarely preserved in troodnotids, though these characters are more

the lacrimal not contacting the maxilla is firstly reported in troodontids as observed in this new

specimen. A vertical columnar process of the articular is a typical character only reported in

probably plesiomorphic in deinonychosaurians and secondarily lost in derived troodontids. As in

Archaeopteryx (Elanowski, 2001), 3D reconstruction of the palate shows that the pterygopalatine

fenestra is long in this new specimen, whereas this fenestra is small in ornithomimosaurs

(Osmólska, Roniewicz \& Barsbold, 1972) and therizinosaurs (Clark, Maryañska \& Barsbold,

2004), and absent in oviraptorosaurs (Elzanowski, 1999) and other avialans (except for

Archaeopteryx). Therefore, the long pterygopalatine fenestra is possibly plesiomorphic for

Paraves in accordance with the conclusion that the pterygoid process of the palatine has an

apparently lengthening trend toward the basal Avialae (Tsuihiji et al., 2014), and secondarily lost in derived avialans.

\section{CONCLUSION}

PMOL-AD00102, a new specimen referred to Sinovenator changii, is described in detail with the assistance of the CT-scan data. More cranial and cervical anatomies and diagnostic features of Sinovenator changii are revealed, such as a well-developed medial shelf on the jugal, a slender 
990

991

992

993

994

995

996

997

998

999

1000

1001

1002

1003

1004

1005

1006

1007

1008

1009

1010

bar in the parasphenoid recess, a lateral groove on the pterygoid flange of the ectopterygoid, and

the lateral surface of the anterior cervical vertebrae bearing two pneumatic foramina.

In addition, we find the braincase of Sinovenator changii is not as primitive as previously

suggested, although it still shows an intermediate state between derived troodontids and non-

troodontid paravians in having an initial stage of the subotic recess and the otosphenoidal crest.

Moreover, our new observation on PMOL-AD00102 has revealed several new and/or

detailed anatomical information on the quadrate-quadratojugal articulation, the stapes, the

epipterygoid, the atlantal ribs, etc.

\section{ACKNOWLEDGEMENTS}

We thank Prof. Ke-Qin Gao and Dr. Jia Jia (Peking University), Dr. Hong-Yu Yi (IVPP), and Mr.

Qin-Fang Fang (China University of Geosciences) for their help in CT scan. We also thank the

academic editor Dr. Hans-Dieter Sues and the three reviewers including Dr. Takanobu Tsuihiji,

Dr. Mark Loewen, and one anonymous reviewer for their helpful comments and suggestions that greatly improved the quality of our manuscript.

\section{REFERENCES}

Alexander OA, Sues HD. 2007. A new troodontid (Dinosauria: Theropoda) from the Cenomanian of Uzbekistan, with a review of troodontid records from the territories of the former Soviet Union. Journal of Vertebrate Paleontology 27:87-98 DOI 10.1671/02724634(2007)27[87:ANTDTF]2.0.CO;2. 
1011 Barsbold R, Osmólska H. 1999. The skull of Velociraptor (Theropoda) from the Late Cretaceous

1012

1013

1014

1015

1016

1017

1018

1019

1020

1021

1022

1023

1024

1025

1026

1027

1028

1029

1030

of Mongolia. Acta Palaeontologica Polonica 44:189-219.

Barsbold R, Osmólska H, Kurzanov SM. 1987. On a new troodontid (Dinosauria, Theropoda)

from the Early Cretaceous of Mongolia. Acta Palaeontologica Polonica 32:121-132.

Chang S-C, Gao K-G, Zhou C-F, Jourdan F. 2017. New chronostratigraphic constraints on the Yixian Formation with implications for the Jehol Biota. Palaeogeography

Palaeoclimatology Palaeoecology 487:399-406 DOI 10.1016/j.palaeo.2017.09.026.

Chapelle K, Choiniere JN. 2018. A revised cranial description of Massospondylus carinatus Owen (Dinosauria:Sauropodomorpha) based on computed tomographic scans and a review of cranial characters for basal Sauropodomorpha. PeerJ 6:e4224 DOI 10.7717/peerj.4224.

Clark JM, Norell MA, Rowe T. 2002 Cranial anatomy of Citipati osmolskae (Theropoda, Oviraptorosauria), and a reinterpretation of the holotype of Oviraptor philoceratops. American Museum Novitates 3364:1-24 DOI 10.1206/00030082(2002)364<0001:CAOCOT>2.0.CO;2.

Clark JM, Maryañska T, Barsbold R. 2004. Therizinosauroidea. In: Weishampel DB, Dodson P, Osmólska H, eds. The Dinosauria. Second Edition. Berkeley: University of California Press, $151-164$.

Colbert EH, Ostrom JH. 1958. Dinosaur stapes. American Museum Novitates 1900:1-20. Colbert EH, Russell DA. 1969. The small Cretaceous dinosaur Dromaeosaurus. American Museum Novitates 2380:1-49. 
1031 Currie PJ. 1985. Cranial anatomy of Stenonychosaurus inequalis (Saurischia: Theropoda) and its 1032 bearing on the origin of birds. Canadian Journal of Earth Sciences 22:1643-1658 DOI

1033 10.1139/e85-173.

1034

1035

1036

1037

1038

1039

1040

1041

1042

1043

1044

1045

1046

1047

1048

1049

1050

1051

Currie PJ. 1987a. Theropods of the Judith River Formation of Dinosaur Provincial Park, Alberta, Canada. In: Currie PJ, Koster EH, eds. Fourth Symposium on Mesozoic Terrestrial Ecosystems, Short Papers. Occasional Paper, Royal Tyrrell Museum of Palaeontology, 5260.

Currie PJ. 1987b. Bird-like characteristics of the jaws and teeth of troodontid theropods (Dinosauria, Saurischia). Journal of Vertebrate Paleontology 7:72-81 DOI 10.1080/02724634.1987.10011638.

Currie PJ. 1995. New information on the anatomy and relationships of Dromaeosaurus albertensis (Dinosauria: Theropoda). Journal of Vertebrate Paleontology 15:576-591 DOI 10.1080/02724634.1995.10011250.

Currie PJ. 2003. Cranial anatomy of tyrannosaurid dinosaurs from the Late Cretaceous of Alberta, Canada. Acta Palaeontologica Polonica 48:191-226.

Currie PJ, Zhao X-J. 1993. A new troodontid (Dinosauria, Theropoda) braincase from the Dinosaur Park Formation (Campanian) of Alberta. Canadian Journal of Earth Sciences 30:2231-2247 DOI 10.1139/e93-194.

Currie PJ, Dong Z-M. 2001. New information on Cretaceous troodontids (Dinosauria, Theropoda) from the People's Republic of China. Canadian Journal of Earth Sciences 38:1753-1766 DOI 10.1139/e01-065. 
1052 Elzanowski A. 1999. A comparison of the jaw skeleton in theropods and birds, with a description 1053 of the palate in the Oviraptoridae. Smithsonian Contributions to Paleobiology 89:311-323.

1054 Elzanowski A. 2001. A novel reconstruction of the skull of Archaeopteryx. Netherlands Journal 1055 of Zoology 51:207-215 DOI 10.1163/156854201X00279.

1056

1057

1058

1059

1060

1061

1062

1063

1064

1065

1066

1067

1068

1069

1070

1071
Elzanowski A, Wellnhofer P. 1996. Cranial morphology of Archaeopteryx: evidence from the seventh skeleton. Journal of Vertebrate Paleontology 16:81-94 DOI 10.1080/02724634.1996.10011286.

Gao C-L, Morschhauser EM, Varricchio DJ, Liu J, Zhao B. 2012. A second soundly sleeping dragon: new anatomical details of the Chinese troodontid Mei long with implications for phylogeny and taphonomy. PLoS ONE 7:e45203 DOI 10.1371/journal.pone.0045203.

Gauthier J. 1986. Saurischian monophyly and the origin of birds. Memoirs of the California Academy of Sciences 8:1-55.

Gilmore CW. 1924. On Troodon validus, an ornithopodus dinosaur from the Belly River Cretaceous of Alberta, Canada. Bulletin of the Department of Geology, University of Alberta 1:1-143

Goloboff PA, Farris JS, Nixon KC. 2015. TNT: tree analysis using new technology, v.1.5 (Willi Hennig Society Edition). Available at http://www.zmuc.dk/public/phylogeny/tnt. Accessed 29 August 2017.

Ji Q, Ji S-A, Lü J-C, You H-L, Chen W, Liu Y-Q, Liu Y-X. 2005. First avialian bird from China (Jinfengopteryx elegans gen. et sp. nov.). Geological Bulletin of China 24:197-210. 
1072 Ji S-A, Ji Q. 2007. Jinfengopteryx compared to Archaeopteryx, with comments on the mosaic 1073 evolution of long-tailed avialan birds. Acta Geologica Sinica 81:337-343 DOI

1074 10.1111/j.1755-6724.2007.tb00957.x.

1075

1076

1077

1078

1079

1080

1081

1082

1083

1084

1085

1086

1087

1088

1089

1090

1091

Lü J-C, Xu L, Liu Y-Q, Zhang X-L, Jia S-H, Ji Q. 2010. A new troodontid theropod from the Late Cretaceous of central China, and the radiation of Asian troodontids. Acta Palaeontologica Polonica 55:381-388.

Madsen JH. 1976. Allosaurus fragilis: a revised osteology. Utah Geological and Mineralogical Survey Bulletin 109:3-163.

Makovicky PJ, Norell MA. 1998. A partial ornithomimid braincase from Ukhaa Tolgod (Upper Cretaceous, Mongolia). American Museum Novitates 3247:1-16.

Makovicky PJ, Norell MA. 2004. Troodontidae. In: Weishampel DB, Dodson P, Osmólska H, eds. The Dinosauria. Second Edition. Berkeley: University of California Press, 184-195.

Makovicky PJ, Norell MA, Clark JM, Rowe T. 2003. Osteology and Relationships of Byronosaurus jaffei (Theropoda: Troodontidae). American Museum Novitates 63:1-32 DOI 10.1206/0003-0082(2003)402<0001:OAROBJ>2.0.CO;2.

Marsh OC. 1881. Principal characters of American Jurassic dinosaurs. Part V. American Journal of Science, Series 3 21:417-423.

Mayr G, Pohl B, Hartman S, Peters DS. 2007. The tenth skeletal specimen of Archaeopteryx. Zoological Journal of the Linnean Society 149:97-116 DOI 10.1111/j.10963642.2006.00245.x. 
1092 Norell MA, Hwang SH. 2004. A troodontid dinosaur from Ukhaa Tolgod (Late Cretaceous

1093

1094

1095

1096

1097

1098

1099

1100

1101

1102

1103

1104

1105

1106

1107

1108

1109

1110

1111
Mongolia). American Museum Novitates 38:1-9 DOI 10.1206/0003-

0082(2004)446<0001:ATDFUT>2.0.CO;2.

Norell MA, Makovicky PJ. 2004. Dromaeosauridae. In: Weishampel DB, Dodson P, Osmólska

H, eds. The Dinosauria. Second Edition. Berkeley: University of California Press, 196-209.

Norell MA, Makovicky PJ, Clark JM. 2000. A new troodontid theropod from Ukhaa Tolgod,

Mongolia. Journal of Vertebrate Paleontology 20:7-11 DOI 10.1671/0272-

4634(2000)020[0007:ANTTFU]2.0.CO;2.

Norell MA, Clark JM, Turner AH, Makovicky PJ, Barsbord R, Rowe T. 2006. A new

dromaeosaurid theropod from Ukhaa Tolgod (Ömnögov, Mongolia). American Museum

Novitates 3545:1-51 DOI 10.1206/0003-0082(2006)3545[1:ANDTFU]2.0.CO;2.

Norell MA, Makovicky PJ, Bever GS, Balanoff AM, Clark JM, Barsbold R, Rowe T. 2009. A

review of the Mongolian Cretaceous dinosaur Saurornithoides (Troodontidae: Theropoda).

American Museum Novitates 3654:1-63 DOI 10.1206/648.1.

Osmólska H, Roniewicz E, Barsbold R. 1972. A new dinosaur, Gallimimus bullatus n. gen. n. sp. (Ornithomimidae) from the Upper Cretaceous of Mongolia. Acta Palaeontologica Polonica 27:103-143.

Osmólska H, Currie PJ, Barsbold R. 2004. Oviraptorosauria. In: Weishampel DB, Dodson P, Osmólska H, eds. The Dinosauria. Second Edition. Berkeley: University of California Press, $165-183$. 
1112

1113

1114

1115

1116

1117

1118

1119

1120

1121

1122

1123

1124

1125

1126

1127

1128

1129

1130

1131

1132

Osborn HF. 1924. Three new Theropoda, Protoceratops zone, central Mongolia. American Museum Novitates 144:1-12.

Ostrom JH. 1969. Osteology of Deinonychus antirrhopus, an unusual theropod from the Lower Cretaceous of Montana. Bulletin of the Peabody Museum of Natural History 30:1-165.

Pei R, Li Q-G, Meng Q-M, Gao K-Q, Norell MA. 2014. A new specimen of Microraptor (Theropoda: Dromaeosauridae) from the Lower Cretaceous of western Liaoning, China. American Museum Novitates 3821:1-28 DOI 10.1206/3821.1.

Pei R, Norell MA, Barta DE, Bever GS, Pittman M, Xu X. 2017a. Osteology of a new Late Cretaceous troodontid specimen from Ukhaa Tolgod, Ömnögovi Aimag, Mongolia. American Museum Novitates 3889:1-47 DOI 10.1206/3889.1.

Pei R, Li Q-G, Meng Q-J, Norell MA, Gao K-Q. 2017b. New specimens of Anchiornis huxleyi (Theropoda: Paraves) from the Late Jurassic of northeastern China. Bulletin of the American Museum of Natural History 411:1-67 DOI 10.1206/0003-0090-411.1.1.

Rauhut OWM. 2014. New observations on the skull of Archaeopteryx. Paläontologische Zeitschrift 88:211-221 DOI 10.1007/s12542-013-0186-0.

Rauhut OWM, Foth C, Tischlinger H. 2018. The oldest Archaeopteryx (Theropoda: Avialiae): a new specimen from the Kimmeridgian/Tithonian boundary of Schamhaupten, Bavaria. PeerJ 6:e4191 DOI 10.7717/peerj.4191.

Russell DA, Dong Z-M. 1993. A nearly complete skeleton of a new troodontid dinosaur from the Early Cretaceous of the Ordos Basin, Inner Mongolia, People's Republic of China. Canadian Journal of Earth Sciences 30:2163-2173 DOI 10.1139/e93-187. 
1133 Sereno PC, Novas FE. 1993. The skull and neck of the basal theropod Herrerasaurus

1134 ischigualastensis. Journal of Vertebrate Paleontology 13:451-476 DOI

1135 10.1080/02724634.1994.10011525.

1136

1137

1138

1139

1140

1141

1142

1143

1144

1145

1146

1147

1148

1149

1150

1151

dinosaur from the Lower Cretaceous Yixian Formation of Liaoning Province, China. Acta Geologica Sinica 91:763-780 DOI 10.1111/1755-6724.13307.

Shen C Z, Zhao B, Gao C-L, Lü J-C, Kundrát M. 2017b. A new troodontid dinosaur (Liaoningvenator curriei gen. et sp. nov.) from the Early Cretaceous Yixian Formation in western Liaoning province. Acta Geoscientica Sinica 38:359-371 DOI 10.3975/cagsb.2017.03.06.

Sues HD. 1978. A new small theropod dinosaur from the Judith River Formation (Campanian) of Alberta Canada. Zoological Journal of the Linnean Society 62:381-400 DOI 10.1111/j.1096-3642.1978.tb01049.x.

Tsuihiji T. 2017. The atlas rib in Archaeopteryx and its evolutionary implications. Journal of Vertebrate Paleontology 37:e1342093 DOI 10.1080/02724634.2017.1342093.

Tsuihiji T, Barsbold R, Watabe M, Tsogtbaatar K, Chinzorig T, Fujiyama Y, Suzukiet S. 2014. An exquisitely preserved troodontid theropod with new information on the palatal structure from the Upper Cretaceous of Mongolia. Naturwissenschaften 101:131-142

DOI 10.1007/s00114-014-1143-9. 
1152 Turner AH, Makovicky PJ, Norell MA. 2012. A review of dromaeosaurid systematics and 1153 paravian phylogeny. Bulletin of the American Museum of Natural History 371:1-206 DOI

1154 1155 1156 1157 1158 1159 1160 1161 1162 1163 1164 1165 1166 1167 1168 1169 1170 $10.1206 / 748.1$.

Witmer LM, Ridgely RC. 2009. New insights into the brain, braincase, and ear region of tyrannosaurs (Dinosauria, Theropoda), with implications for sensory organization and behavior. Anatomical Record-advances in Integrative Anatomy \& Evolutionary Biology 292:1266-1296 DOI: 10.1002/ar.20983.

Xu X. 2002. Deinonychosaurian fossils from the Jehol Group of western Liaoning and the coelurosaurian evolution. Ph.D. Thesis, Chinese Academy of Sciences.

Xu X, Wu X-C. 2001. Cranial morphology of Sinornithosaurus millenii Xu et al. 1999 (Dinosauria: Theropoda: Dromaeosauridae) from the Yixian Formation of Liaoning, China. Canadian Journal of Earth Sciences 38:1739-1752 DOI 10.1139/e01-082.

Xu X, Norell MA. 2004. A new troodontid dinosaur from China with avian-like sleeping posture. Nature 431:838-841 DOI 10.1038/nature02898.

Xu X, Wang X-L. 2004. A new troodontid (Theropoda:Troodontidae) from the Lower Cretaceous Yixian Formation of western Liaoning, China. Acta Geologica Sinica 78:22-26 DOI 10.1111/j.1755-6724.2004.tb00671.x.

Xu X, Norell MA, Wang X-L, Makovicky PJ, Wu X-C. 2002. A basal troodontid from the Early Cretaceous of China. Nature 415:780-784DOI 10.1038/415780a. 
1171 Xu X, Choiniere JN, Pittman M, Tan Q-W, Xiao D, Li Z-Q, Tan L, Clark JM, Norrell MA, Hone

1172

1173

1174

1175

1176

1177

1178

1179

1180

1181

1182

1183

1184

1185

1186
DWE, Sullivan C. 2010. A new dromaeosaurid (Dinosauria: Theropoda) from the Upper Cretaceous Wulansuhai Formation of inner Mongolia, China. Zootaxa 2403:1-9.

Xu X, Tan Q-W, Sullivan C, Han F-L, Xiao D. 2011. A short-armed troodontid dinosaur from the Upper Cretaceous of inner Mongolia and its implications for troodontid evolution. PLoS ONE 6:e22916 DOI 10.1371/journal.pone.0022916.

Xu X, Pittman M, Sullivan C, Choiniere JN, Tan Q-W, Clark JM, Norell MA, Wang S. 2015 a. The taxonomic status of the Late Cretaceous dromaeosaurid Linheraptor exquisitus and its implications for dromaeosaurid systematics. Vertebrata PalAsiatica 53:29-62.

Xu X, Zheng X-T, Sullivan C, Wang X-L, Xing L-D, Wang Y, Zhang X-M, O’Connor JK, Zhang F-C, Pan Y-H. 2015b. A bizarre Jurassic maniraptoran theropod with preserved evidence of membranous wings. Nature 521:70-73DOI 10.1038/nature14423.

Xu X, Currie PJ, Pittman M, Xing L-D, Meng Q-J, LüJ-C, Hu D-Y, Yu C-Y. 2017. Mosaic evolution in an asymmetrically feathered troodontid dinosaur with transitional features. Nature Communication 8:14972 DOI 10.1038/ncomms14972. 
Figure 1

Area map showing the fossil locality (marked by an asterisk) of Sinovenator (PMOLAD00102) in Lujiatun Village, Shangyuan, Beipiao City, western Liaoning Province, China.

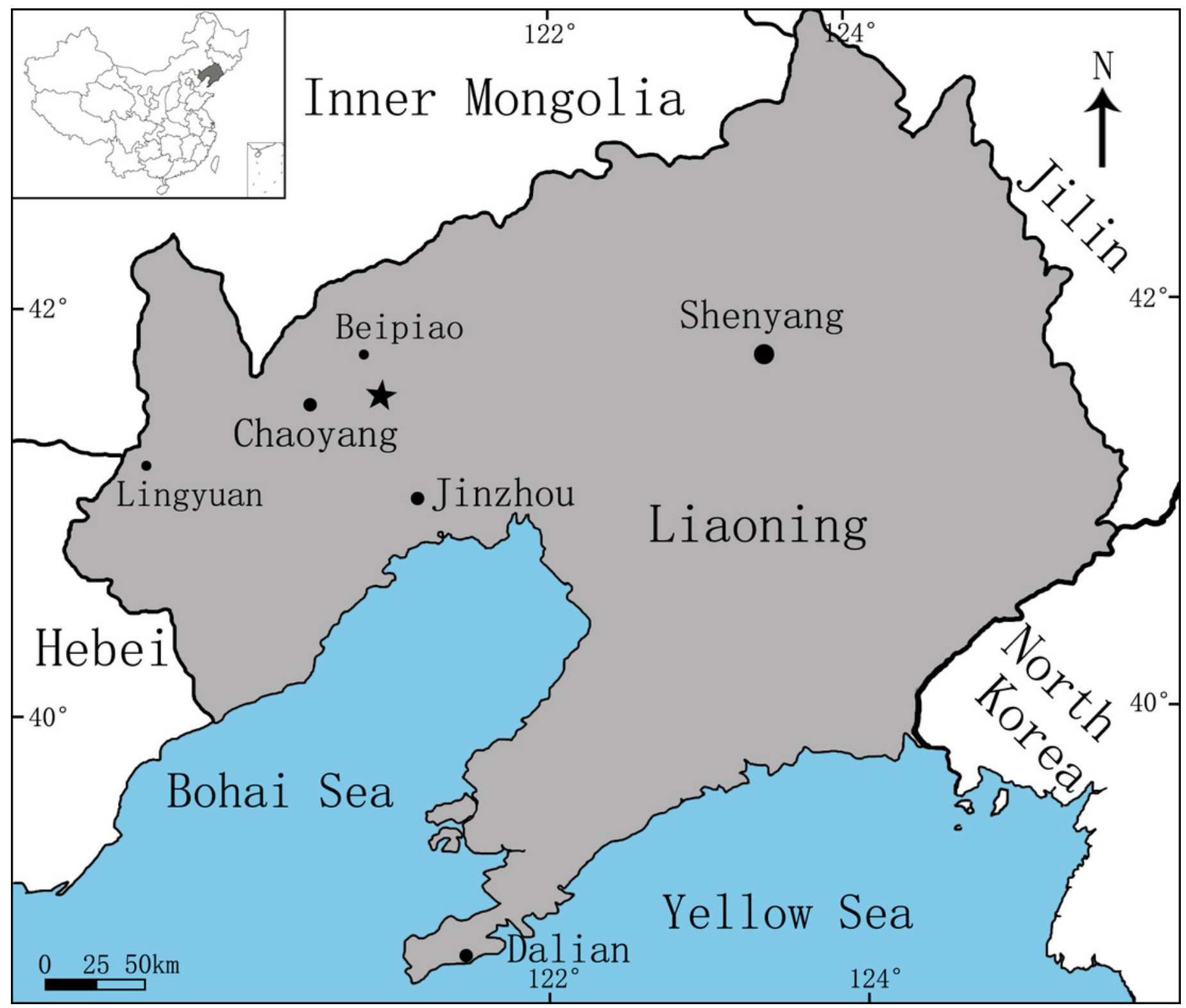




\section{Figure 2}

Skull and mandibles of PMOL-AD00102 in left lateral view.

(A) photograph; (B) CT-rendered image.Abbreviations: an, angular; ax, axis; co, coronoid; $\mathrm{cp}$, cultriform process; cr, cervical ribs; d, dentary; e, epipterygoid; f, frontal; j, jugal; I, lacrimal; Is, laterosphenoid; m, maxilla; n, nasal; p, parietal; pl, palatine; po, postorbital; pop, paroccipital process; pra, prearticular; q, quadrate; qj, quadratojugal; sd, supradentary; sp, splenial; sq, squamosal; su, surangular; v, vomer. 

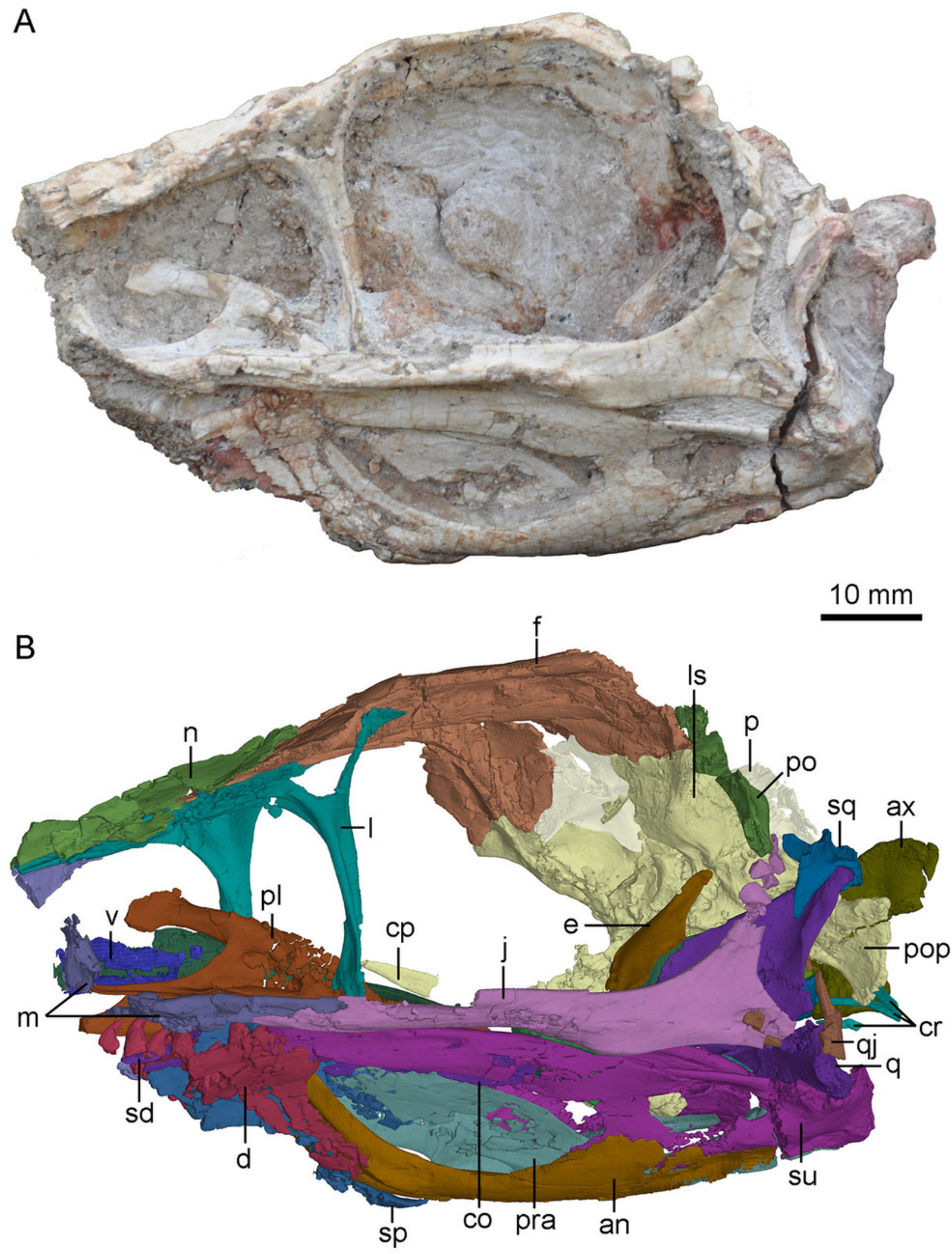


\section{Figure 3}

Skull and mandibles of PMOL-AD00102 in right lateral view.

(A) photograph; (B) CT-rendered image. Abbreviations: an, angular; atic, atlantal intercentrum; atna, atlantal neural arch; ax, axis; $c p$, cultriform process; d, dentary; ec, ectopterygoid; f, frontal; j, jugal; I, lacrimal; Is, laterosphenoid; m, maxilla; n, nasal; oc, occipital condyle; p, parietal; pl, palatine; po, postorbital; pop, paroccipital process; pra, prearticular; pro, proatlas; pt, pterygoid; q, quadrate; sp, splenial; sq, squamosal; su, surangular; v, vomer. 

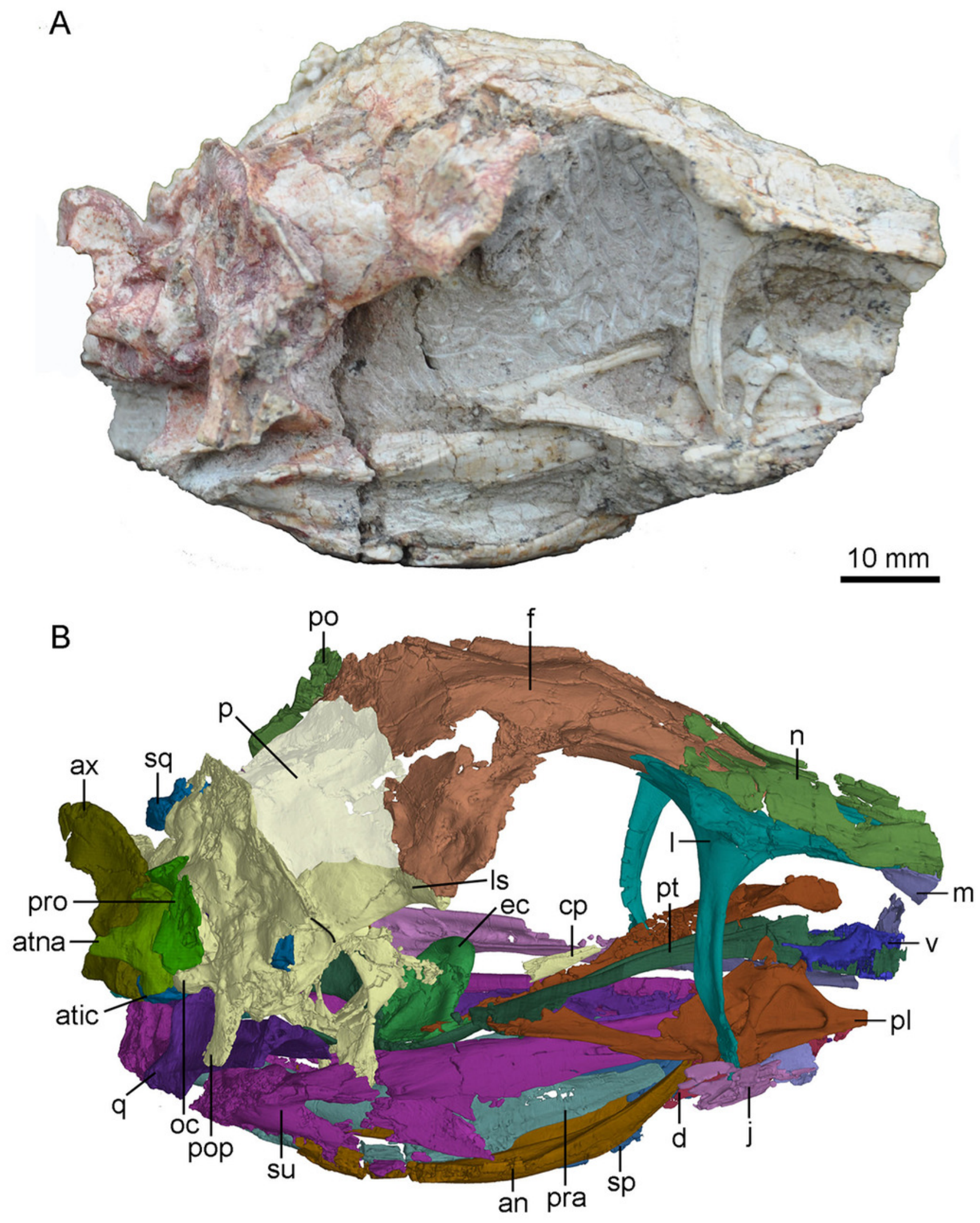


\section{Figure 4}

CT-rendered skull of PMOL-AD00102 in dorsal (A) and ventral (B) views.

Abbreviations: bpt, basipterygoid process; ec, ectopterygoid; f, frontal; j, jugal; I, lacrimal; Is, laterosphenoid; m, maxilla; $\mathrm{n}$, nasal; nc, nuchal crest; oc, occipital condyle; p, parietal; pl, palatine; po, postorbital; pop, paroccipital process; pt, pterygoid; q, quadrate; qj, quadratojugal; rf, ridge on frontal; s?, a possible stapes fragment; sc, saggital crest; sq, squamosal; $v$, vomer. 

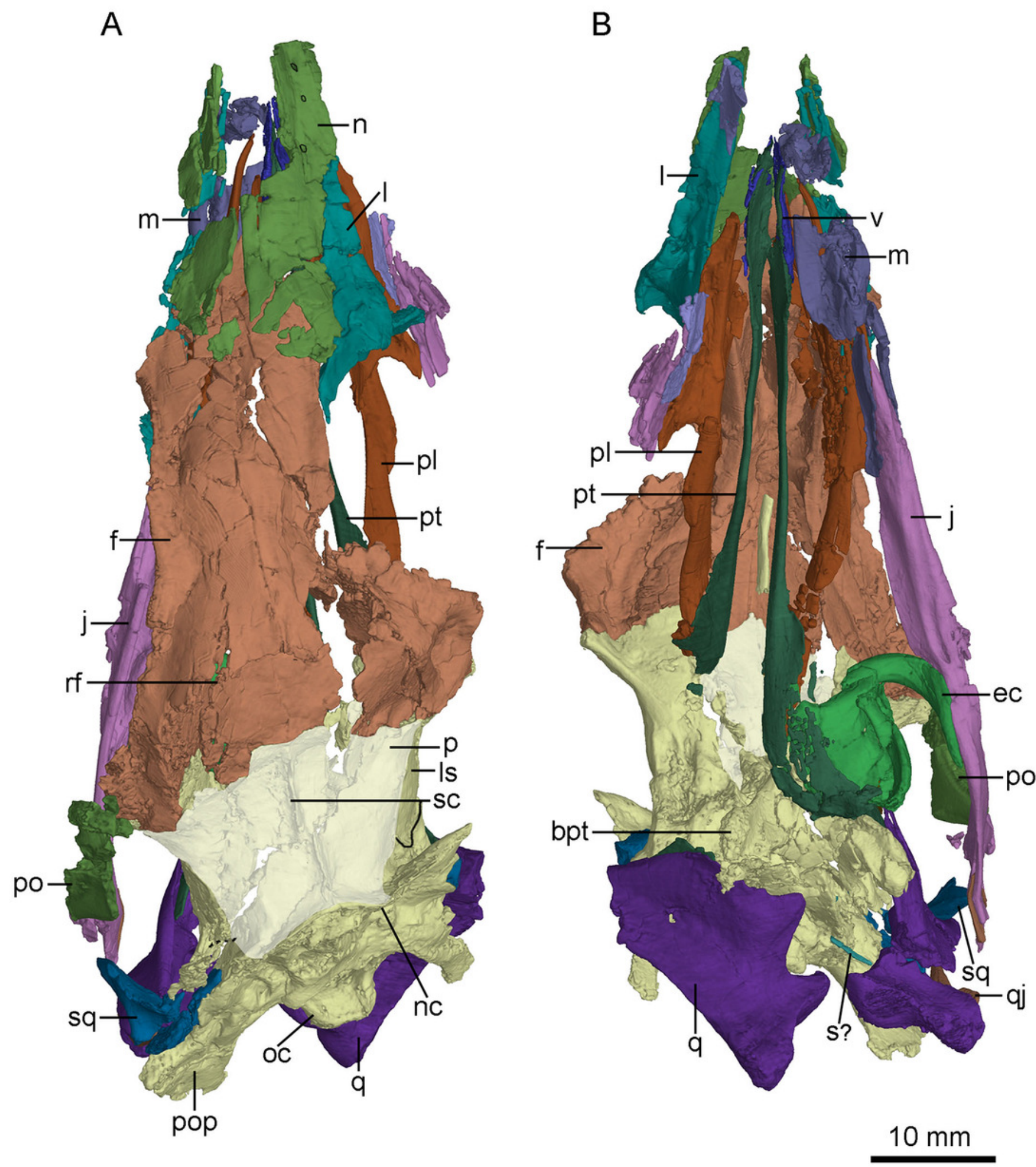


\section{Figure 5}

CT-rendered left lacrimal of PMOL-AD00102 in lateral (A) and medial (B) views.

Abbreviations: fo, fossa; lap, anterior process of lacrimal; If, lacrimal foramen; Id, lacrimal duct; Ipp, posterior process of lacrimal; pb, preorbital bar; soc, supraorbital crest.

A

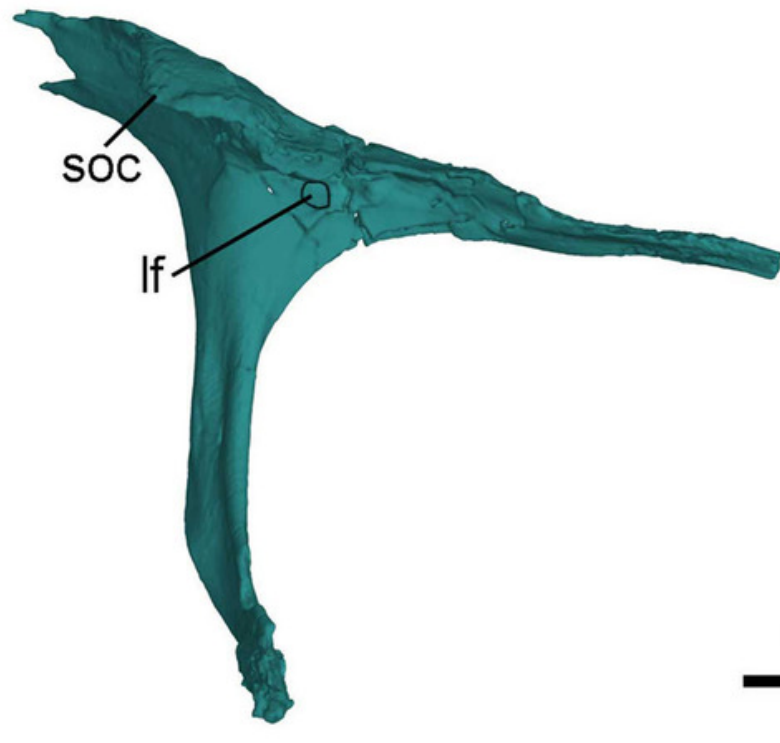

B

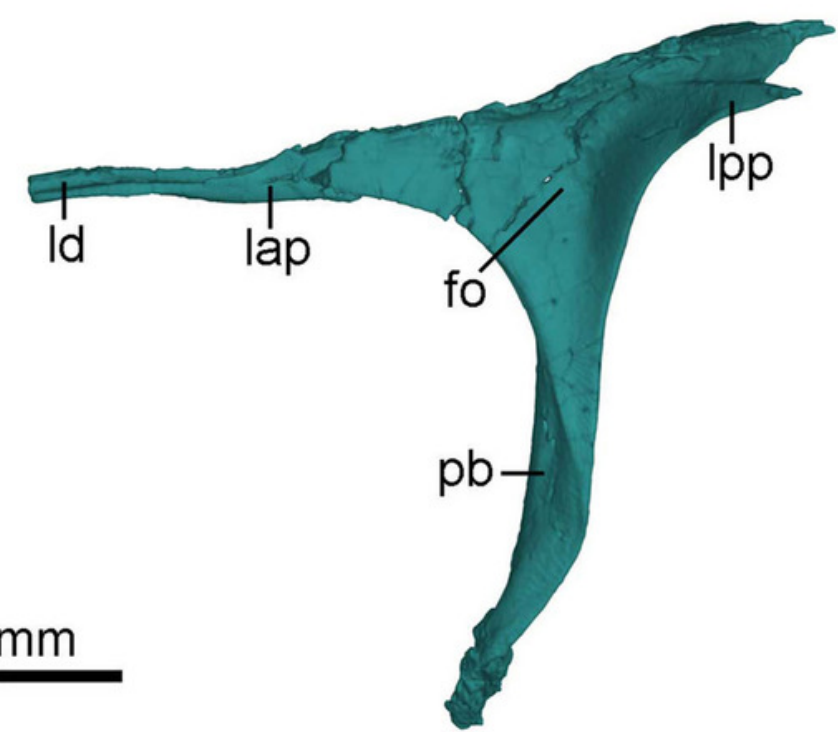




\section{Figure 6}

CT-rendered left jugal of PMOL-AD00102 in dorsal (A) and medial (B) views, and a crosssectional CT image of jugal (C).

Abbreviations: dp, dorsal prong of quadratojugal process of jugal; ect, ectopterygoid contact; jd, depression on jugal; jf, fossa on jugal; jg, groove on jugal; jt, trough on jugal; ms, medial shelf on jugal; pop, postorbital process of jugal; qjp, quadratojugal process of jugal; sop, suborbital process of jugal; vp, ventral prong of quadratojugal process of jugal.

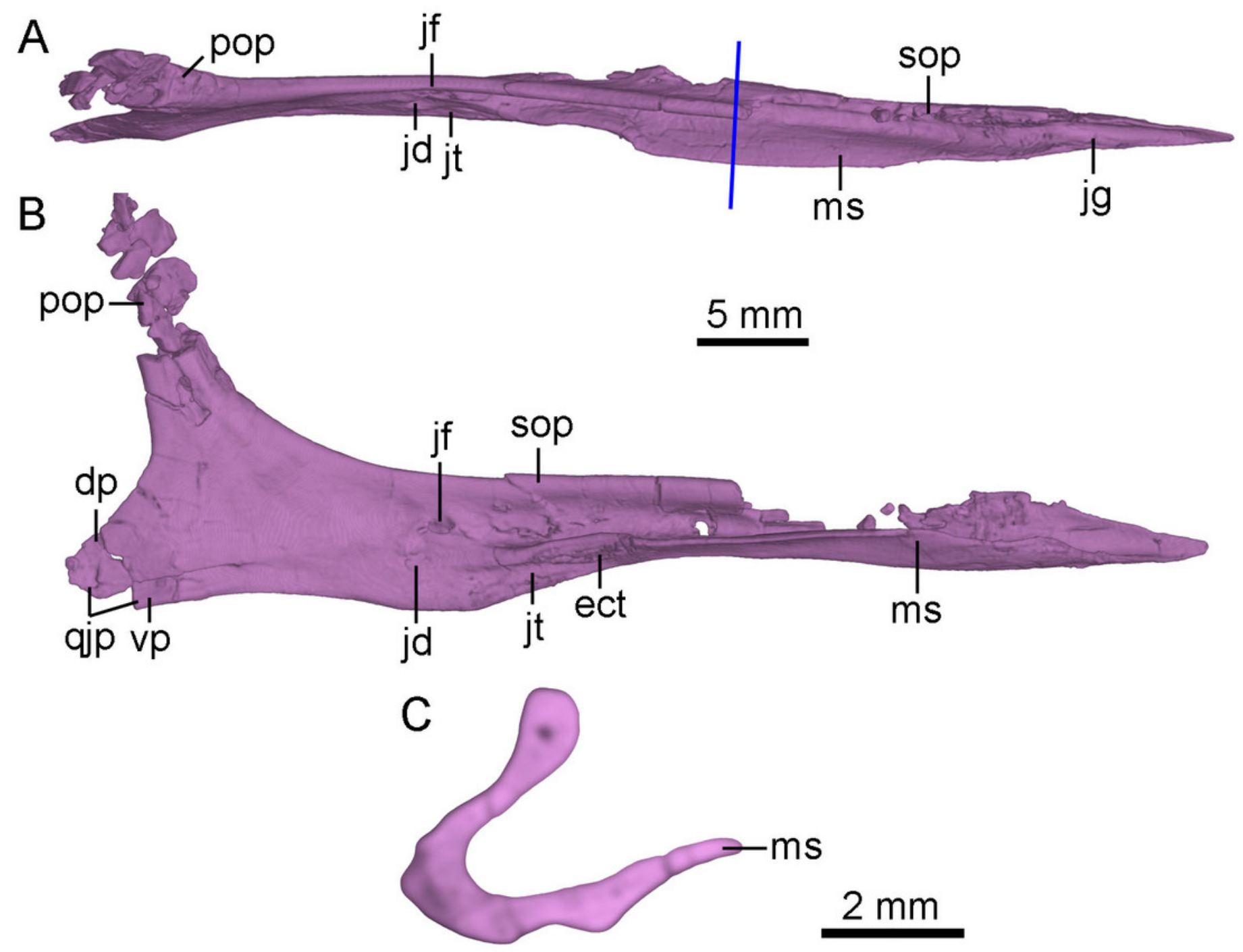




\section{Figure 7}

CT-rendered palatal elements of PMOL-AD00102.

(A) palate in dorsal view; (B) left palatal elements in lateral view; (C) left palatal elements in medial view. Abbreviations: e, epipterygoid; ec, ectopterygoid; in, internal naris; iptv, interpterygoid vacuity; pf, palatine fenestra; pl, palatine; ppf, posterior pneumatic fenestra; pt, pterygoid; ptf, pterygopalatine fenestra; q, quadrate; qr, quadrate ridge; stf, subtemporal fenestra; v, vomer. 
A

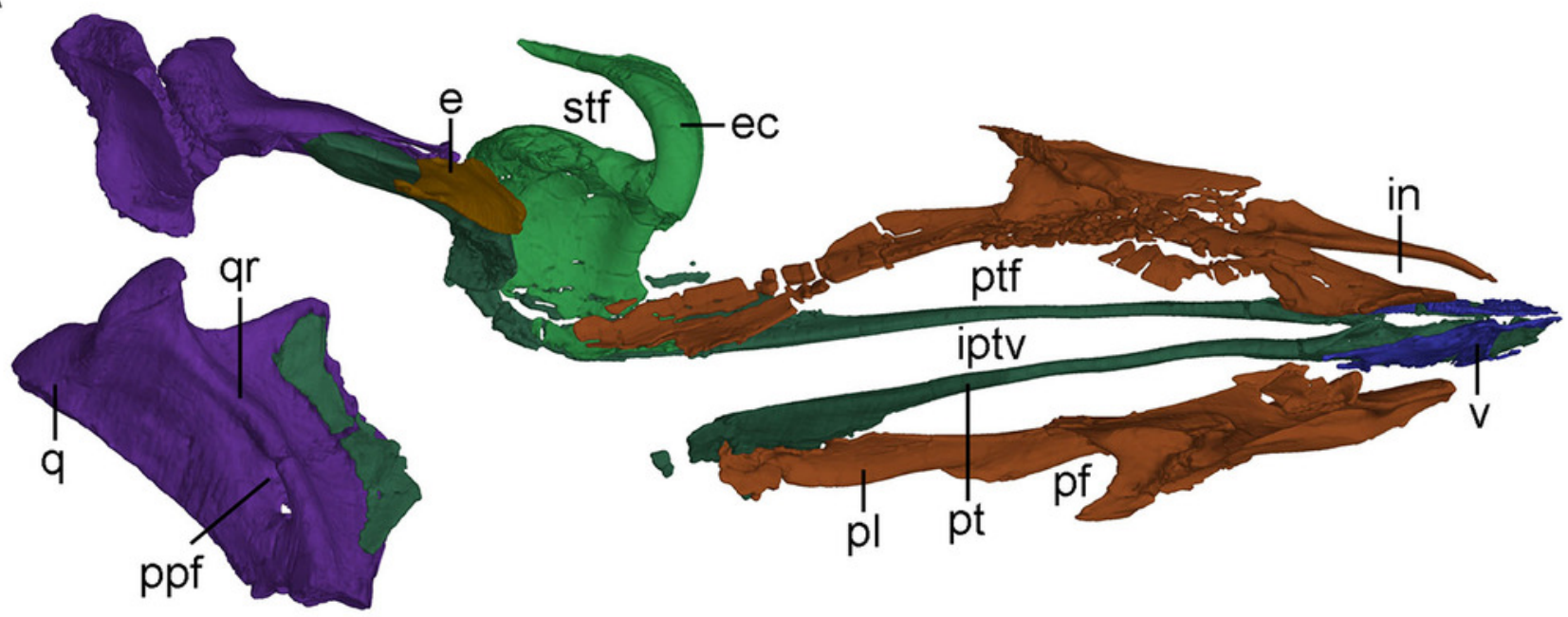

B
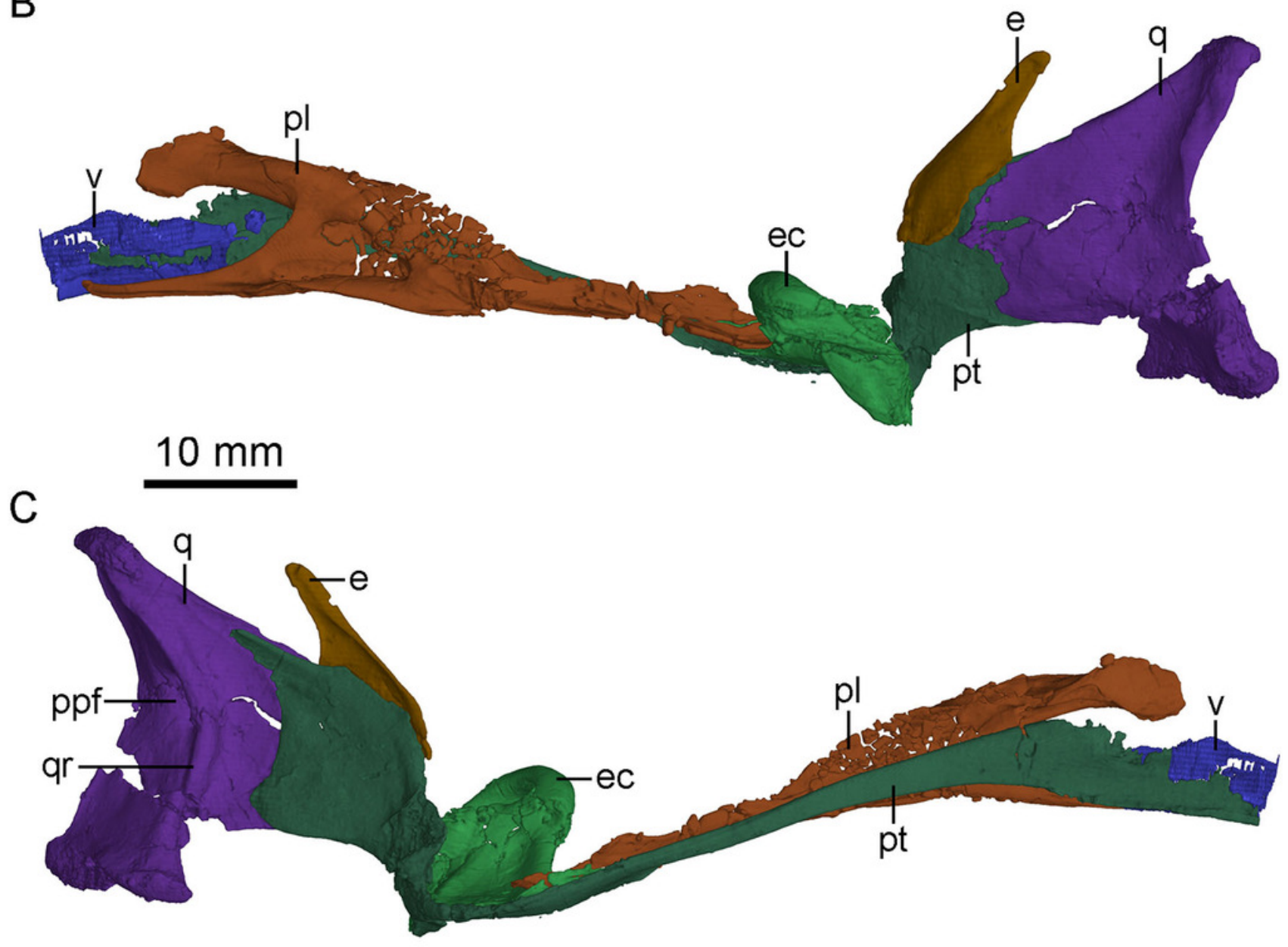


\section{Figure 8}

CT-rendered braincase of PMOL-AD00102in right lateral view (A) and ventral view (B).

Abbreviations: bpt, basipterygoid process; bptr, basipterygoid recess; br, basisphenoid recess; bt, basal tuber; cc, crista cranii; cp, cultriform process; dr, dorsal tympanic recess; f, frontal; fo, fossa; Is, laterosphenoid; nc, nuchal crest; oc, occipital condyle; p, parietal; pop, paroccipital process; pro, prootic; psr, parasphenoid recess; sc, sagittal crest; scr, subcondylar recess; sf, slot on frontal; sor, subotic recess. 


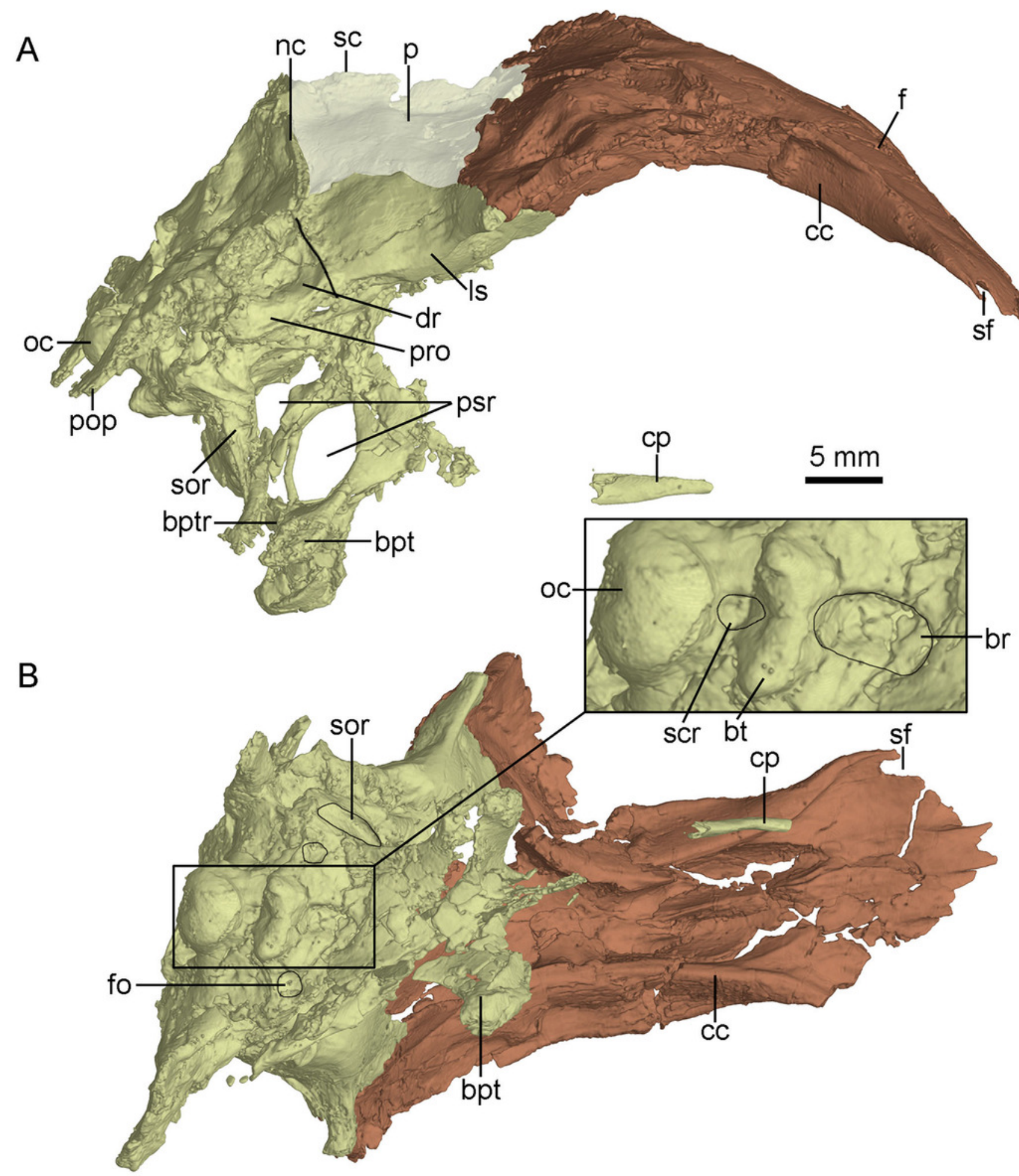




\section{Figure 9}

CT-rendered braincase of PMOL-AD00102 in posterior view.

Abbreviations: bpt, basipterygoid process; bt, basal tuber; f, frontal; fm, foramen magnum; ls, laterosphenoid; nc, nuchal crest; p, parietal; pop, paroccipital process; oc, occipital condyle; vcmp, posterior canal of middle cerebral vein; $\mathrm{X}, \mathrm{XI}$, tenth and eleventh cranial nerve exit; XII, twelfth cranial nerve exit. 


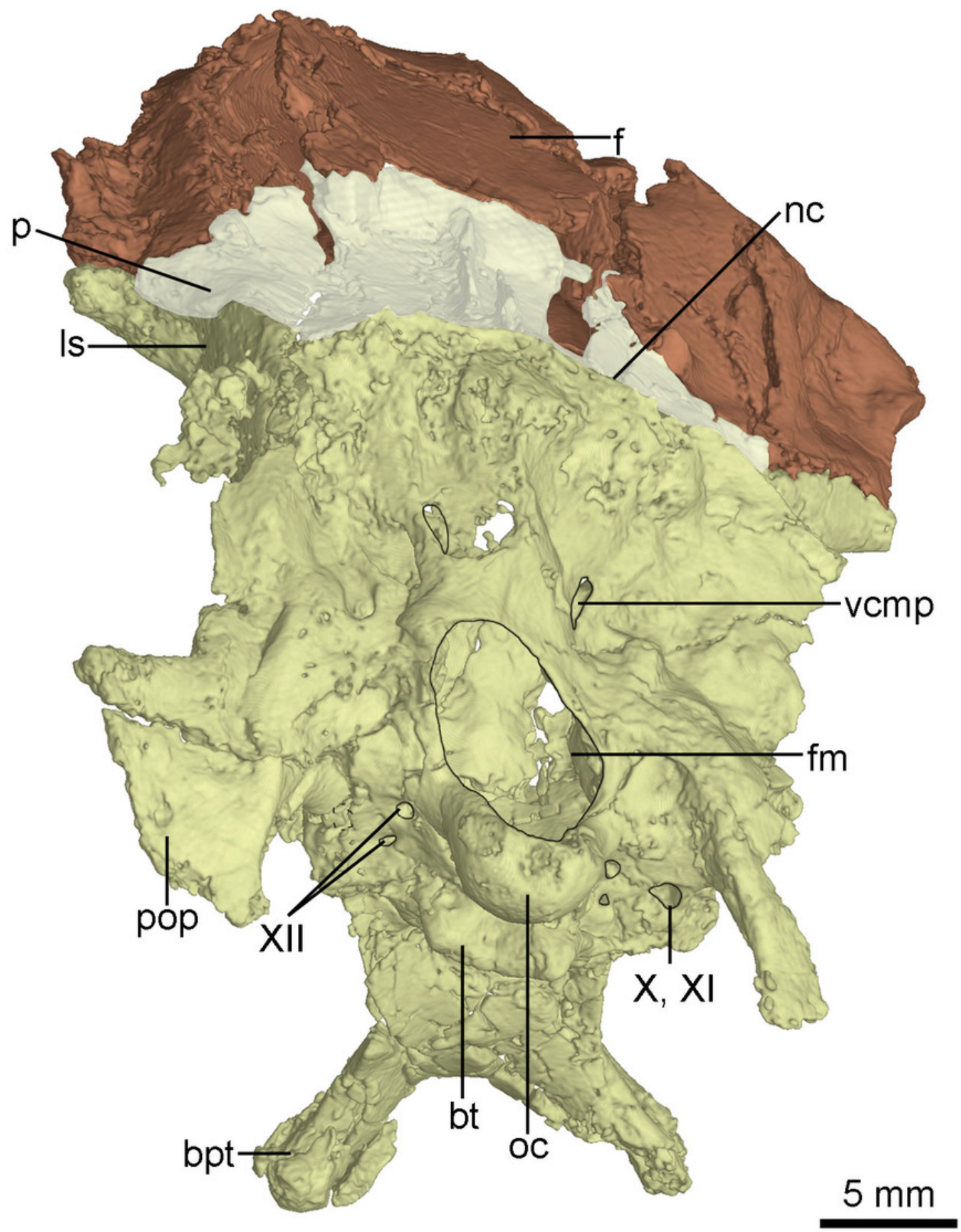




\section{Figure 10}

CT-rendered braincase of PMOL-AD00102 in left lateral view.

Abbreviations: at, accessory tympanic recess; bpt, basipterygoid process; bptr, basipterygoid recess; cif, crista interfenestralis; ctr, caudal tympanic recess; dr, dorsal tympanic recess; fo, fenestra ovalis; fpr, fenestra pseudorotunda; Is, laterosphenoid; mf, metotic fissure; nc, nuchal crest; oc, occipital condyle; otc, otosphenoidal crest; p, parietal; pld, perilymphatic duct; pls, pit on laterosphenoid; pop, paroccipital process; pro, prootic; psr, parasphenoid recess; III, third cranial nerve exit; IV, fourth cranial nerve exit; V, fifth cranial nerve exit; VII, seventh cranial nerve exit. 


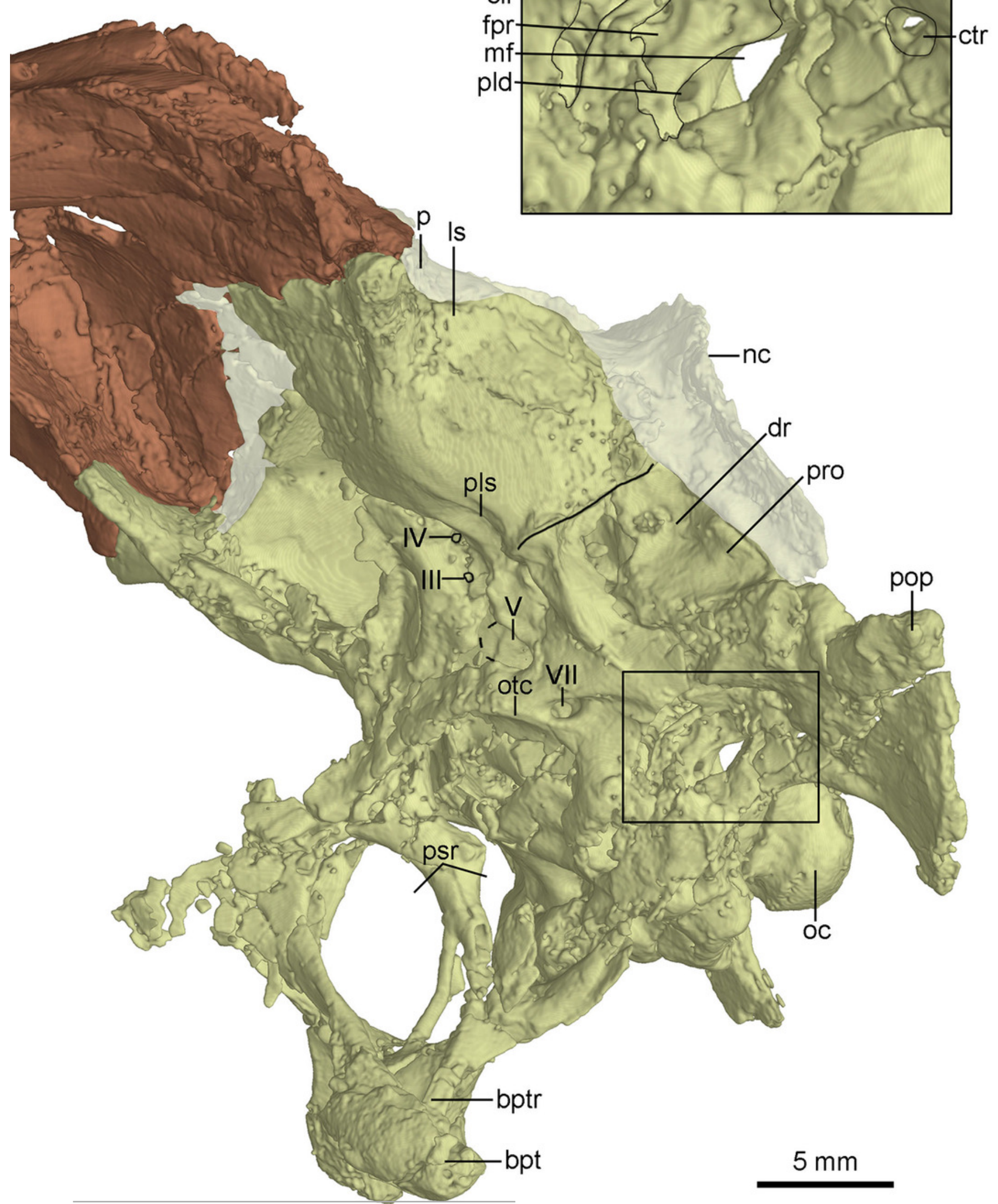




\section{Figure 11}

CT-rendered braincase of PMOL-AD00102 in medial view.

(A) anterior part of the right side; (B) posterior part of the left side. Abbreviations: ed, endolymphatic duct; fopt, fossa of optic lobe; fr, floccular recess; mf, metotic fissure; oc, occipital condyle; pld, perilymphatic duct; vcm, groove for middle cerebral vein; vcmp, posterior canal of middle cerebral vein; $\mathrm{V}$, fifth cranial nerve exit; VII, seventh cranial nerve exit; VIII, eighth cranial nerve exit; XII, twelfth cranial nerve exit. 


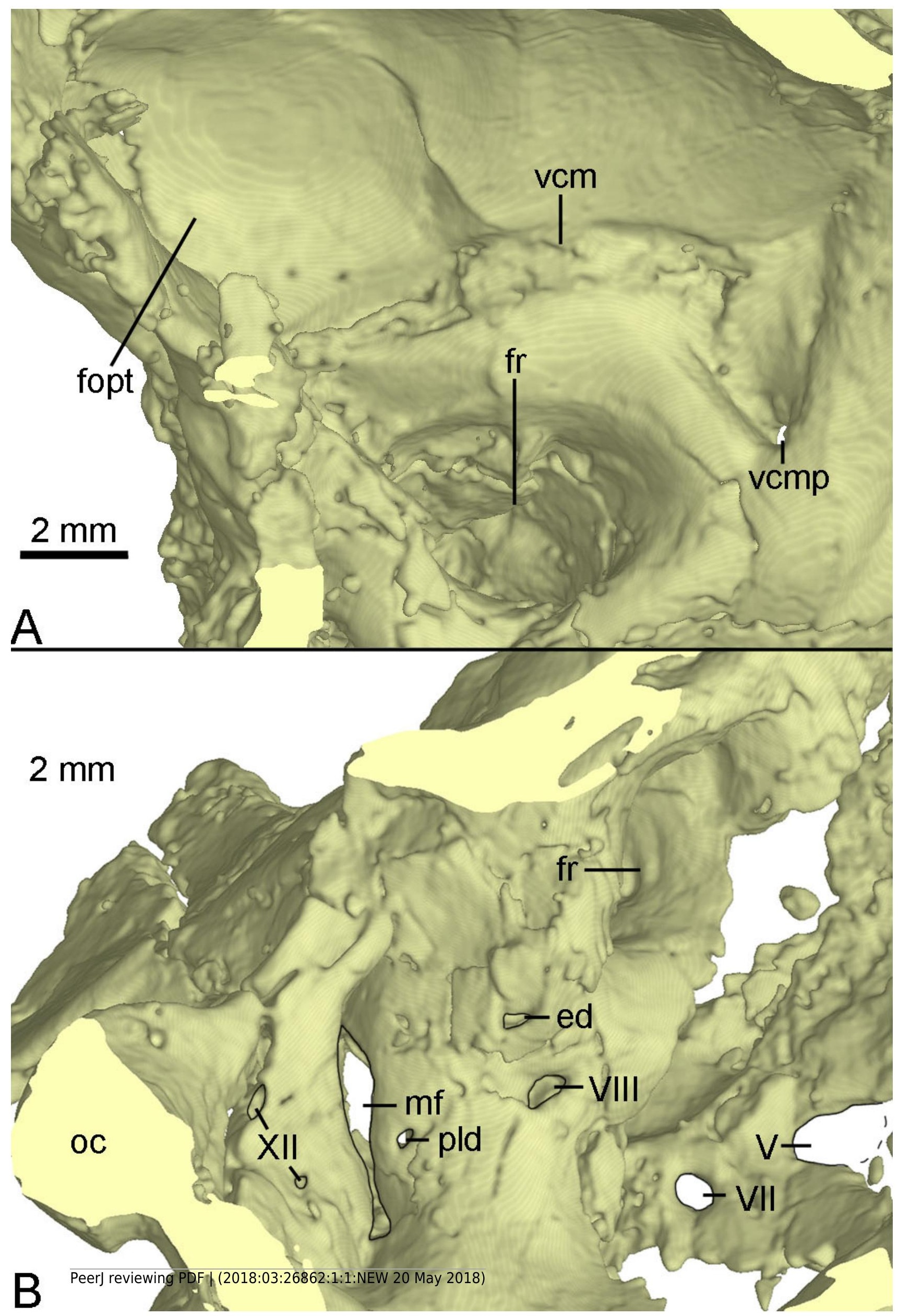




\section{Figure 12}

CT-rendered left stapes of PMOL-AD00102 in lateral (A) and dorsal (B) views.

Abbreviation: $\mathrm{ft}$, footplate.

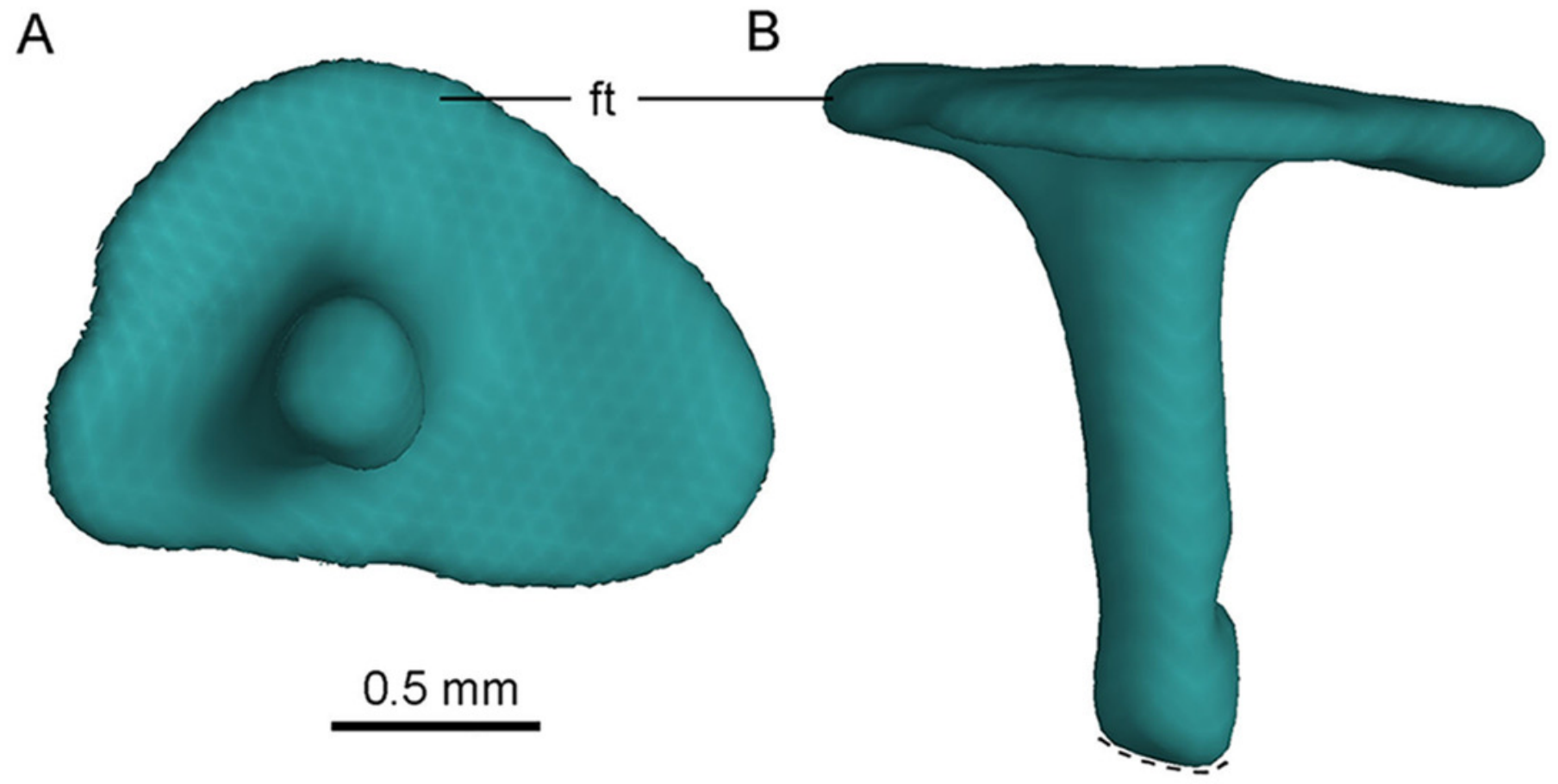




\section{Figure 13}

CT-rendered left $(A, B, C)$ and right (D, E) mandibles of PMOL-AD00102, and a crosssectional $C T$ image of surangular in $(F)$.

$(A, D)$ in lateral views; (B) in dorsal view; $(C, E)$ in medial views. Abbreviations: af, adductor fossa; an, angular; ar, articular; asf, anterior surangular foramen; co, coronoid; d, dentary; emf, external mandibular fenestra; imf, internal mandibular fenestra; pra, prearticular; saf, surangular foramen; sd, supradentary; sp, splenial; su, surangular; vcp, vertical columnar process. 


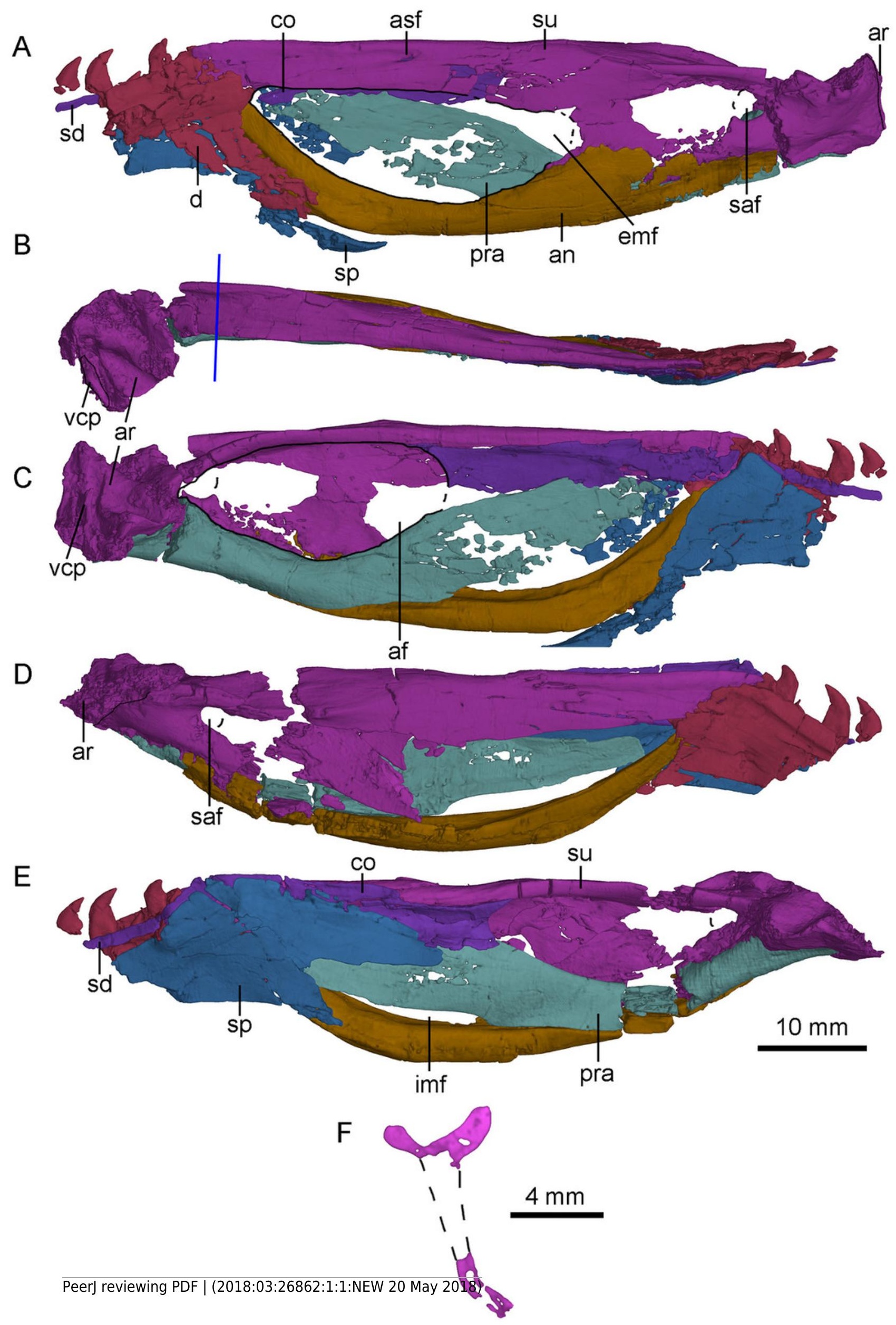




\section{Figure 14}

Cervical vertebrae of PMOL-AD00102.

(A) Photograph; (B) line drawing. Abbreviations: atic, atlantal intercentrum; atna, atlantal neural arch; atr, atlantal rib; ax, axis; c3-c6, third through sixth cervical vertebrae; di, diapophysis; ep, epipophysis; pa, parapophysis; pl, pleurocoel; pro, proatlas; r3-r5, third through fifth cervical ribs. 

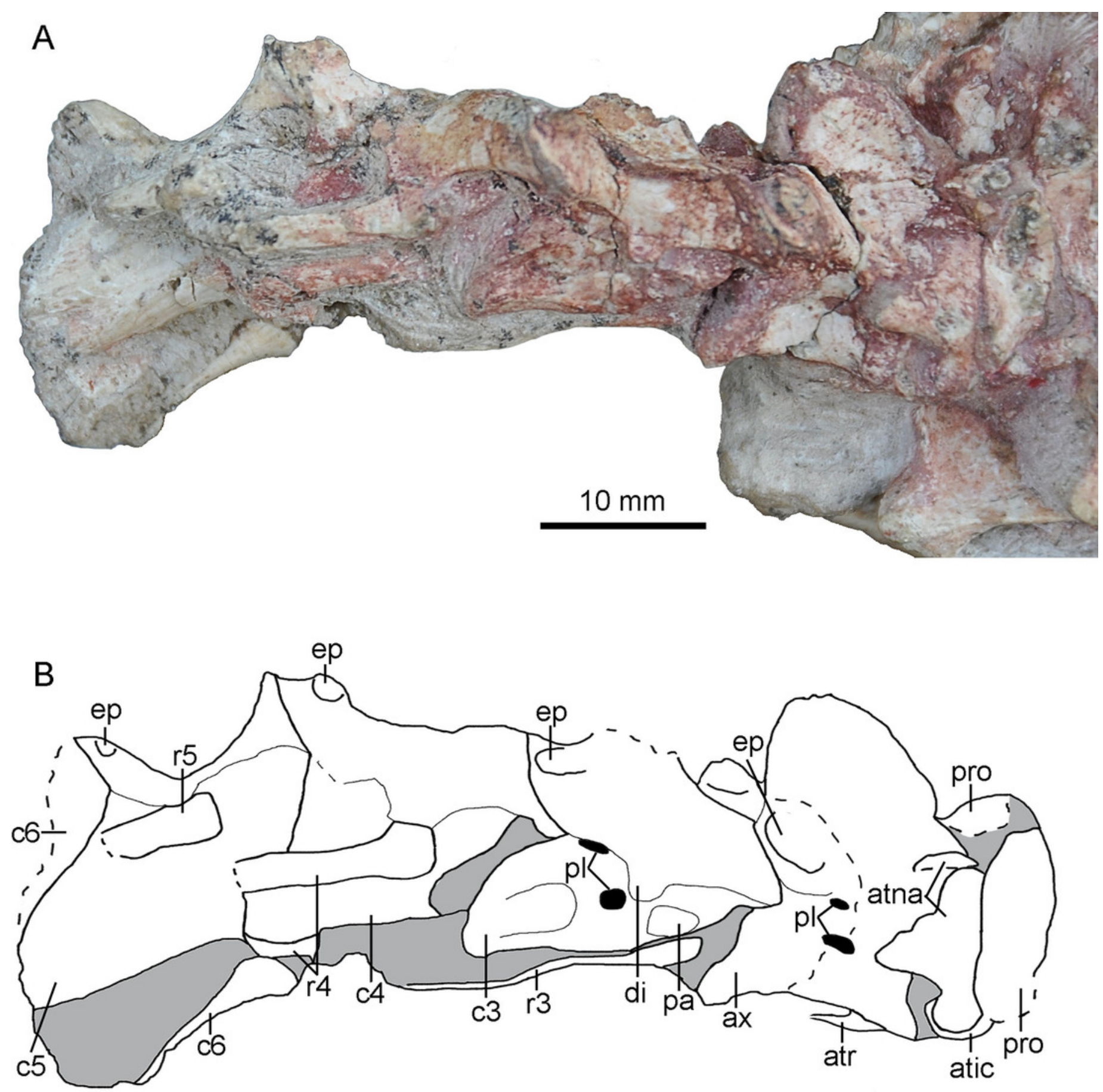


\section{Figure 15}

Selected CT-rendered cervical vertebrae of PMOL-AD00102.

Atlantal intercentrum in anterior (A), dorsal (B), posterior $(C)$ and ventral (D) views; left proatlas in lateral (E) and medial (F) views; axis, axial rib and atlantal ribs in left lateral view (G); right atlantal neural arch in lateral $(\mathrm{H})$ and medial (I) views. Abbreviations: amp, ampullae; ara, atlantal rib articulation; atr, atlantal rib; axi, axial intercentrum; axr, axial rib; ep, epipophysis; od, odontoid; ped, pedicle; pp, posterior process of proatlas; prz, prezygapophysis.

A

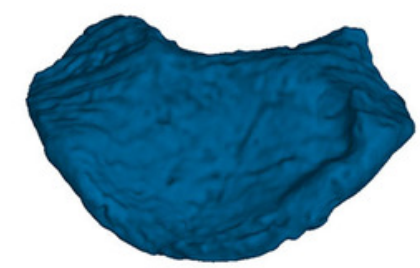

B

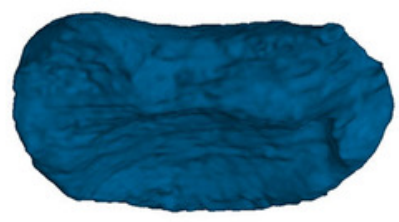

E

E

G
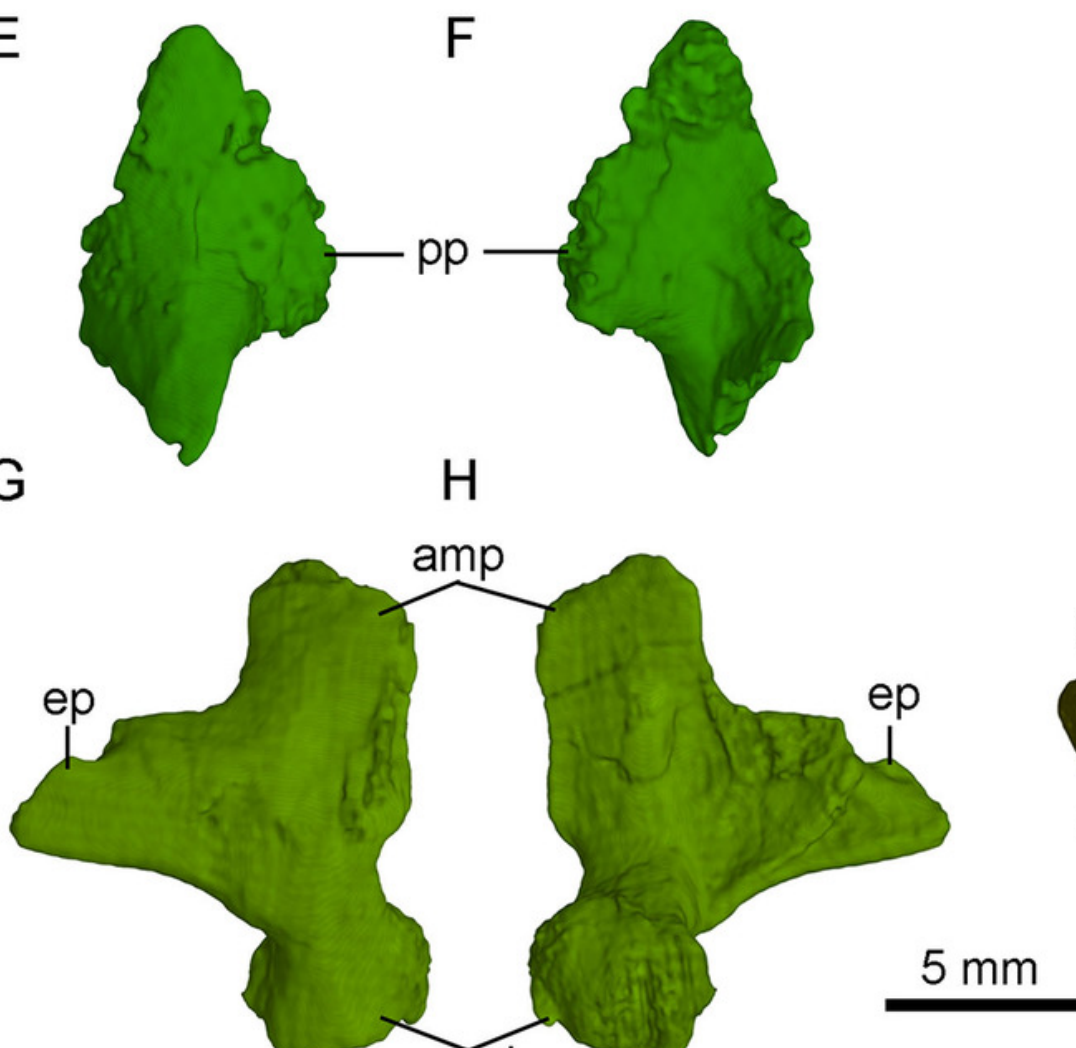

C

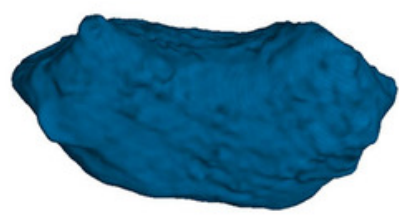

D

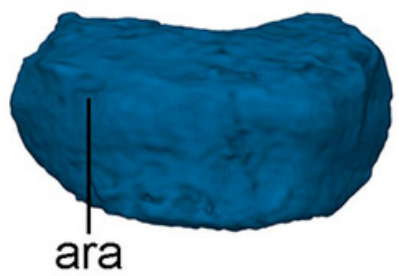

ara

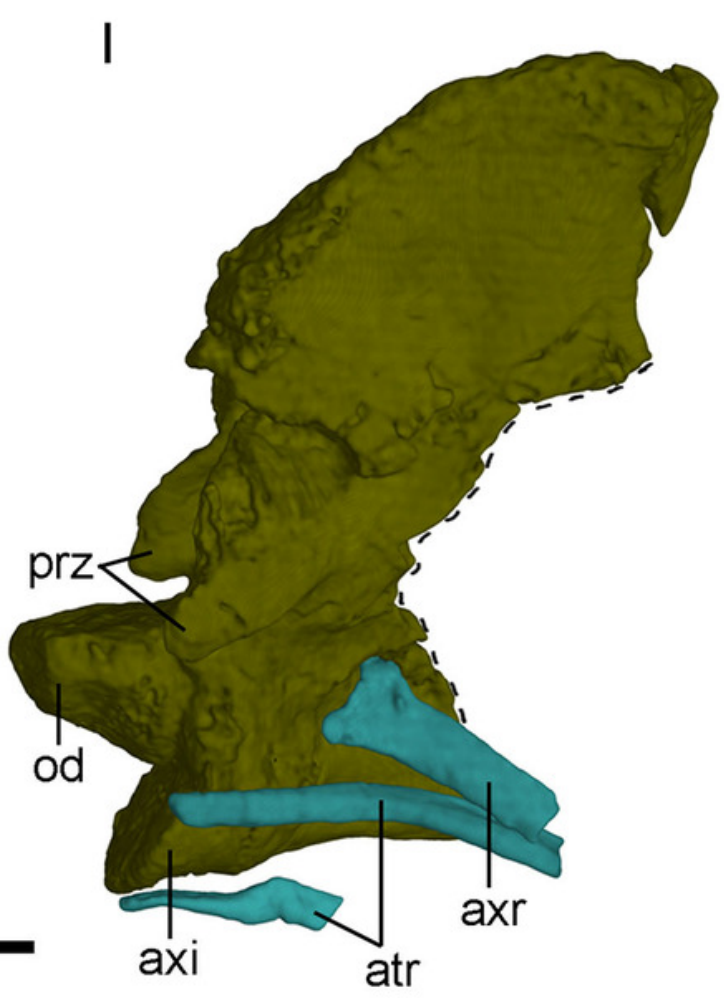




\section{Figure 16}

Phylogenetic reconstruction.

(A) Troodontid portion of the strict consensus of 40 MPTs ( $T L=1433$ steps, $\mathrm{Cl}=0.317, \mathrm{RI}=$ 0.739), showing phylogenetic positions of Sinovenator and PMOL-AD00102; (B) Troodontid portion of the strict consensus of $20 \mathrm{MPTs}$ ( $\mathrm{TL}=1428$ steps, $\mathrm{Cl}=0.318, \mathrm{RI}=0.739$ ), showing phylogenetic position of Sinovenator.

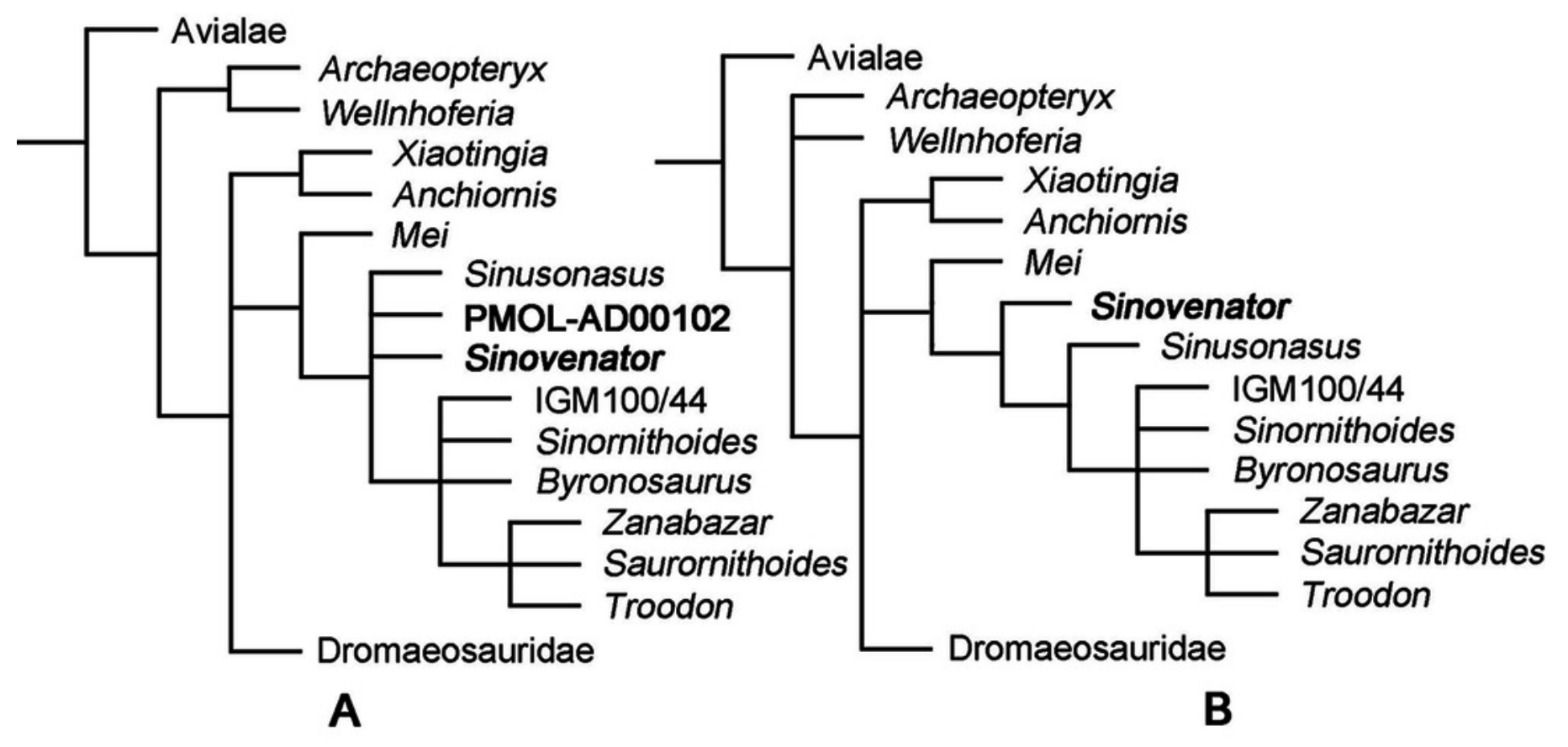

